\title{
Conversational Agents in Health Care: Scoping Review and Conceptual Analysis
}

Lorainne Tudor $\mathrm{Car}^{1,2}$, MD, MSc, PhD; Dhakshenya Ardhithy Dhinagaran ${ }^{1}$, BSc (hons); Bhone Myint Kyaw ${ }^{1}$, MBBS, MSc, PhD; Tobias Kowatsch ${ }^{3,4,5}$, MSc, PhD; Shafiq Joty ${ }^{6}$, MSc, PhD; Yin-Leng Theng ${ }^{7}, \mathrm{PhD}$; Rifat Atun ${ }^{8}, \mathrm{MBBS}$ MBA, FRCGP, FFPH, FRCP

\footnotetext{
${ }^{1}$ Family Medicine and Primary Care, Lee Kong Chian School of Medicine, Nanyang Technological University Singapore, Singapore

${ }^{2}$ Department of Primary Care and Public Health, School of Public Health, Imperial College London, London, United Kingdom

${ }^{3}$ Future Health Technologies programme, Campus for Research Excellence and Technological Enterprise (CREATE), Singapore-ETH Centre, Singapore

${ }^{4}$ Center for Digital Health Interventions, Department of Management, Technology, and Economics, ETH Zurich, Zurich, Switzerland

${ }^{5}$ Center for Digital Health Interventions, Institute of Technology Management, University of St Gallen, St Gallen, Switzerland

${ }^{6}$ School of Computer Sciences and Engineering, Nanyang Technological University Singapore, Singapore

${ }^{7}$ Centre for Healthy and Sustainable Cities, Nanyang Technological University, Singapore

${ }^{8}$ Department of Global Health and Population, Harvard T.H. Chan School of Public Health, Harvard University, Boston, MA, United States
}

\section{Corresponding Author:}

Lorainne Tudor Car, MD, MSc, PhD

Family Medicine and Primary Care

Lee Kong Chian School of Medicine

Nanyang Technological University Singapore

11 Mandalay Road

Singapore

Phone: 6569041258

Fax: 6569041258

Email: lorainne.tudor.car@ntu.edu.sg

\section{Abstract}

Background: Conversational agents, also known as chatbots, are computer programs designed to simulate human text or verbal conversations. They are increasingly used in a range of fields, including health care. By enabling better accessibility, personalization, and efficiency, conversational agents have the potential to improve patient care.

Objective: This study aimed to review the current applications, gaps, and challenges in the literature on conversational agents in health care and provide recommendations for their future research, design, and application.

Methods: We performed a scoping review. A broad literature search was performed in MEDLINE (Medical Literature Analysis and Retrieval System Online; Ovid), EMBASE (Excerpta Medica database; Ovid), PubMed, Scopus, and Cochrane Central with the search terms "conversational agents," "conversational AI," "chatbots," and associated synonyms. We also searched the gray literature using sources such as the OCLC (Online Computer Library Center) WorldCat database and ResearchGate in April 2019. Reference lists of relevant articles were checked for further articles. Screening and data extraction were performed in parallel by 2 reviewers. The included evidence was analyzed narratively by employing the principles of thematic analysis.

Results: The literature search yielded 47 study reports (45 articles and 2 ongoing clinical trials) that matched the inclusion criteria. The identified conversational agents were largely delivered via smartphone apps $(n=23)$ and used free text only as the main input $(n=19)$ and output $(n=30)$ modality. Case studies describing chatbot development $(n=18)$ were the most prevalent, and only 11 randomized controlled trials were identified. The 3 most commonly reported conversational agent applications in the literature were treatment and monitoring, health care service support, and patient education.

Conclusions: The literature on conversational agents in health care is largely descriptive and aimed at treatment and monitoring and health service support. It mostly reports on text-based, artificial intelligence-driven, and smartphone app-delivered conversational agents. There is an urgent need for a robust evaluation of diverse health care conversational agents' formats, focusing on their acceptability, safety, and effectiveness. 


\section{KEYWORDS}

conversational agents; chatbots; artificial intelligence; machine learning; mobile phone; health care; scoping review

\section{Introduction}

\section{Background}

Conversational agents or chatbots are computer programs that simulate conversations with users [1]. They are increasingly adopted in many different fields, including finance, commerce, marketing, retail, and fitness, with favorable reception from customers [2]. Conversational agents are often deployed via messaging apps, a website, or a mobile phone app. They can also be integrated into cars and television sets or in the form of a stand-alone device such as speakers. They can converse through a range of methods such as text, image, and voice. Conversational agents that can interpret human speech and respond via synthesized voices as well as manage tasks requested by the user are also known as voice assistants. Some of the most popular voice assistants include Apple's Siri, Amazon's Alexa, Google Assistant, and Microsoft's Cortana, mostly delivered using voice-activated or smart speakers such as Amazon's Echo and Google Home. They are utilized for aiding or executing tasks such as web-based shopping, control of smart home devices, and disseminating news or for entertainment [3-5].

Conversational agents cover a broad spectrum of aptitudes ranging from simple to smart [2]. Simple conversational agents are rule based, meaning that they depend on prewritten keywords and commands programmed by the developer. The user is therefore restricted to predetermined options when answering questions posed by the conversational agents, and there is little or no opportunity for free responses. If a user enters a question or sentence without a single keyword, the conversational agents will be unable to understand the input and will respond with a default message such as "Sorry, I did not understand" [2]. Despite these restrictions, simple conversational agents are increasingly used in executing tasks such as booking appointments, purchasing merchandise, ordering food, and sharing information without the need for human involvement [2].

In contrast, smart conversational agents do not respond with preprepared answers but with adequate suggestions instead. This is enabled by machine learning, a type of artificial intelligence (AI), which allows for broadening of the computer system's capacity through its learning from data (in this case conversations) without being explicitly programmed $[2,6]$. The process whereby the machine translates human commands into a form in which the computer can understand, process, and revert to the user is called natural language processing (NLP)
[6] and natural language understanding or interpretation [6,7]. This degree of programming allows for personalized conversational agents to be generated. Smart conversational agents have the potential to undertake more complex tasks that involve greater interaction, reasoning, prediction, and accuracy. Although the technology behind smart conversational agents is continuously developed, they currently do not have full human-level language abilities, resulting in misunderstanding and users' dissatisfaction [8]. Furthermore, as machine learning algorithms develop, it is becoming increasingly challenging to keep track of their development, evolution, and the reasoning behind their responses. This is known as the black box effect $[9,10]$. Although the black box effect appears to be an unavoidable consequence of the use of $\mathrm{AI}$, there is some emerging research on making AI transparent and explainable [11]. However, at the moment, its use may affect the safety and accuracy of treatment and should be carefully monitored and evaluated when used in health care [9].

The first conversational agent ELIZA was developed by Weizenbaum [12] in 1966, with ELIZA taking on the role of a person-centered Rogerian psychotherapist (Figure 1). This was a groundbreaking contribution to the field of AI and was reported to have a positive impact on patients who communicated with the conversational agent [13]. A step up from ELIZA was achieved when $P A R R Y$, a conversational agent representing a simulated paranoid patient with schizophrenia, was developed $[14,15]$. These first examples of conversational agents, chatterbots (as they were referred to then), in health care were valuable in demonstrating that virtual agents have the potential to mimic human-human conversation and successfully pass the Turing Test, a test of a machine's ability to replicate human intelligence, and the machine passes the test when the tester cannot distinguish it from the human [16].

The literature over the next few decades does not explicitly mention chatbots or conversational agents in health care, but it does refer to talking computers [17-21], a less sophisticated version of today's conversational agents previously used for conducting patient satisfaction surveys [17], altering adult eating habits [18], aiding health care service delivery through diagnosis aid [19], and promoting patient-physician communication [20]. Although not presented in the literature, chatbot Jabberwacky was released in 1988. It was one of the first few AI agents developed for human interaction and entertainment and introduced the shift from text- to voice-operated conversational agents. Soon after, ALICE gained plenty of attention in 1995, after which it went on to win the Loebner Prize 3 times in 2000, 2001, and 2004. 
Figure 1. Evolution of conversational agents from 1966 to 2019.

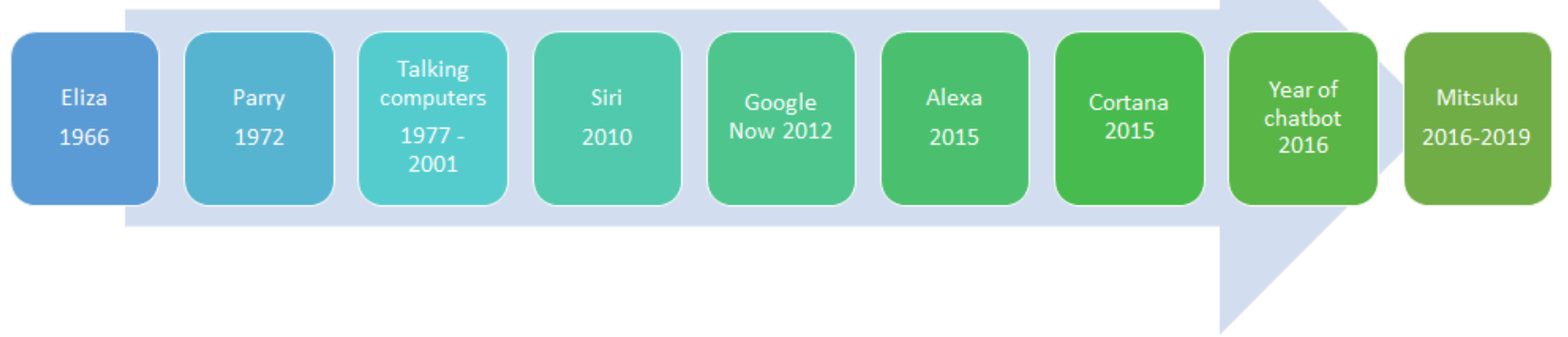

The next big milestone for conversational agents was in 2010 when Apple released Siri. The interest in conversational agents increased exponentially at this point as evidenced by Google, Amazon, and Microsoft all developing their own versions over the coming years: Google now, Alexa, and Cortana, respectively [14]. Year 2016 was named the Year of the Chatbot as a number of major information technology companies started to use conversational agents: Facebook launched its messenger platform for conversational agents, Google announced its procurement of the conversational agent development tool API.ai, LinkedIn revealed its first messaging bot, and Viber released Public Accounts for chatting with businesses [22-25]. Currently, the title of the world's best conversational agent is held by Mitsuku, a 4-time winner of the Loebner Prize, an annual competition in AI [26].

Health care, which has seen a decade of text messaging on smartphones, is an ideal candidate for conversational agent-delivered interventions. Conversational agents enable interactive, 2-way communication, and their text- or speech-based method of communication makes it suitable for a variety of target populations, ranging from young children to older people. The concept of using mobile phone messaging as a health care intervention has been present and increasingly explored in health care research since 2002 [27]. A series of systematic reviews on the use of text messaging for different health disorders have shown that text messaging is an effective and acceptable health care intervention [28,29]. With a global penetration rate of $96 \%$ [28], mobile phones are ubiquitous and avidly used, and can be efficiently harnessed in health care [30]. Conversational agents are increasingly used in diverse fields, including health care, and there is a need to identify different ways and outcomes of the use of conversational agents in health care. Existing reviews on conversational agents focus on a certain subtype of agents such as virtual coaches [31-33] or embodied conversational agents (ECAs) [34] or on specific functionalities of these agents such as behavior change [35] or mental health applications $[36,37]$. Other reviews report solely on the technical aspects of conversational agents such as system architecture and dialogues [38] or on the funding component of health care conversational interfaces [39].

\section{Objectives}

Our objective was to provide a comprehensive overview of the existing research literature on the use of health care-focused conversational agents. We aimed to examine how conversational agents have been employed and evaluated in the literature to date and map out their characteristics. Finally, in line with the observed gaps in the literature, we sought to provide recommendations for future conversational agent research, design, and applications.

\section{Methods}

\section{Search Strategy}

We adopted methodological guidance from an updated version of the Arksey and O'Malley framework with suggestions proposed by Peters et al [40] in 2015 to conduct our scoping review. To identify literature pertaining to the application of conversational agents in health care, a broad literature search was conducted in April 2019 in MEDLINE (Medical Literature Analysis and Retrieval System Online; Ovid), EMBASE (Excerpta Medica database; Ovid), PubMed, Scopus, and Cochrane Central. Given the novelty of the field, the amount of ongoing research happening in the area, and to increase comprehensiveness, we also searched for the gray literature in the OCLC WorldCat database, ResearchGate, Google Scholar, OpenGrey, and the first 10 pages of Google.

We used an extensive list of 63 search terms, including various synonyms for conversational agents (Multimedia Appendix 1). These synonyms were generated using a web-based search and by identifying specific terms or phrases used in the titles of articles discussing health care conversational agents. The reference list of relevant articles and systematic reviews were also searched for further articles related to the review.

\section{Inclusion and Exclusion Criteria}

To map out the current conversational agent applications in health care, we included primary research studies that had conducted an evaluation and reported findings on a conversational agent implemented for a health care-specific purpose. We excluded articles that just presented a proposal for conversational agent development, articles that mentioned conversational agents briefly or as an insignificant part of a review, as well as opinion pieces and articles where primary research was not conducted or discussed. A further point of exclusion was articles with poorly reported data on chatbot assessments where there was minimal or no evaluation data. In addition, we excluded articles concerning ECAs, relational agents, animated conversational agents, or other conversational agents with a visual or animated component. 
ECAs are computer-generated virtual individuals with an animated appearance to enable face-to-face interaction between the user and the system [41]. Relational agents are a type of ECA designed to create long-term deep and meaningful relationships with individuals [42]. ECAs are similar to conversational agents in that conversation is central to their function; however, ECAs are more complex as hand movements and facial expressions can be conveyed to the user as well [41]. The user's interaction may be affected by nonverbal behaviors, graphics, and layout of the program, and it was decided that the complexities associated with ECAs are beyond the scope of this review and were therefore excluded.

\section{Screening, Data Extraction, and Analysis}

Screening of articles for inclusion was performed in 2 stages: title and abstract review and full article review, undertaken independently by 2 reviewers. Following an initial screening of titles and abstracts, full texts were obtained and screened by 2 reviewers. From the included studies, 2 reviewers independently extracted relevant information in an Excel (Microsoft) spreadsheet. We extracted data on the first author, year of publication, source of literature, title of article, type of literature, study design and methods, geographic focus, health care sector, conversational agent name, accessibility of conversational agent, dialogue technique, input and output modalities, and nature of conversational agent's end goal. We piloted the data extraction sheet on at least five articles. Potential discrepancies in the extracted data were discussed between the authors and resolved through discussion and consensus.

We performed a narrative synthesis of the included literature and presented findings on (1) study specifics, such as study design, geographic focus, and type of literature; (2) conversational agent specifics (ie, conversational agent delivery channel, dialogue technique, personality, etc); (3) conversational agent content analysis; and (4) study evaluation findings.

We used the principles of thematic analysis to analyze the content, scope, and personality traits of the conversational agents. Two researchers familiarized themselves with the literature identified, generated the initial codes in relation to personality and content analysis, applied the codes to the included studies, compared their findings, and resolved any discrepancies via discussion.

The need to present information on conversational agent personality was motivated by the concepts presented in the study by de Haan et al [43], which posits that personalities are not just limited to humans but can be extended to nonhuman artifacts to explain their actions and behavior [43]. Furthermore, it states that personality traits are especially important in the design of socially interactive robots, such as conversational agents. The 5 dimensions of personality presented in this paper were derived from the following: extraversion, agreeableness, conscientiousness, emotional stability, and culture. We have used these headings to guide our analysis of the conversational agents' personality traits in this review. We also aimed to identify and analyze the patterns in the description of conversational agents pertaining to personality traits. Multiple codes were sometimes assigned to the same agent where necessary, but this was limited to a maximum of 3 codes to maintain some degree of specificity.

\section{Results}

\section{Search Findings}

The initial database searches yielded 11,401 records, and another 28 records were retrieved through additional sources such as the gray literature sources and screening of reference lists of relevant studies. A total of 196 duplicates were identified and removed, leaving 11,233 titles and abstracts that needed to be screened. Title and abstract screening led to the exclusion of 11,099 records, resulting in 134 full texts that needed to be assessed for eligibility. Of these, 87 articles were excluded, resulting in a final pool of 47 reports comprising 45 studies and 2 ongoing trials (Figure 2). 
Figure 2. PRISMA flow chart.

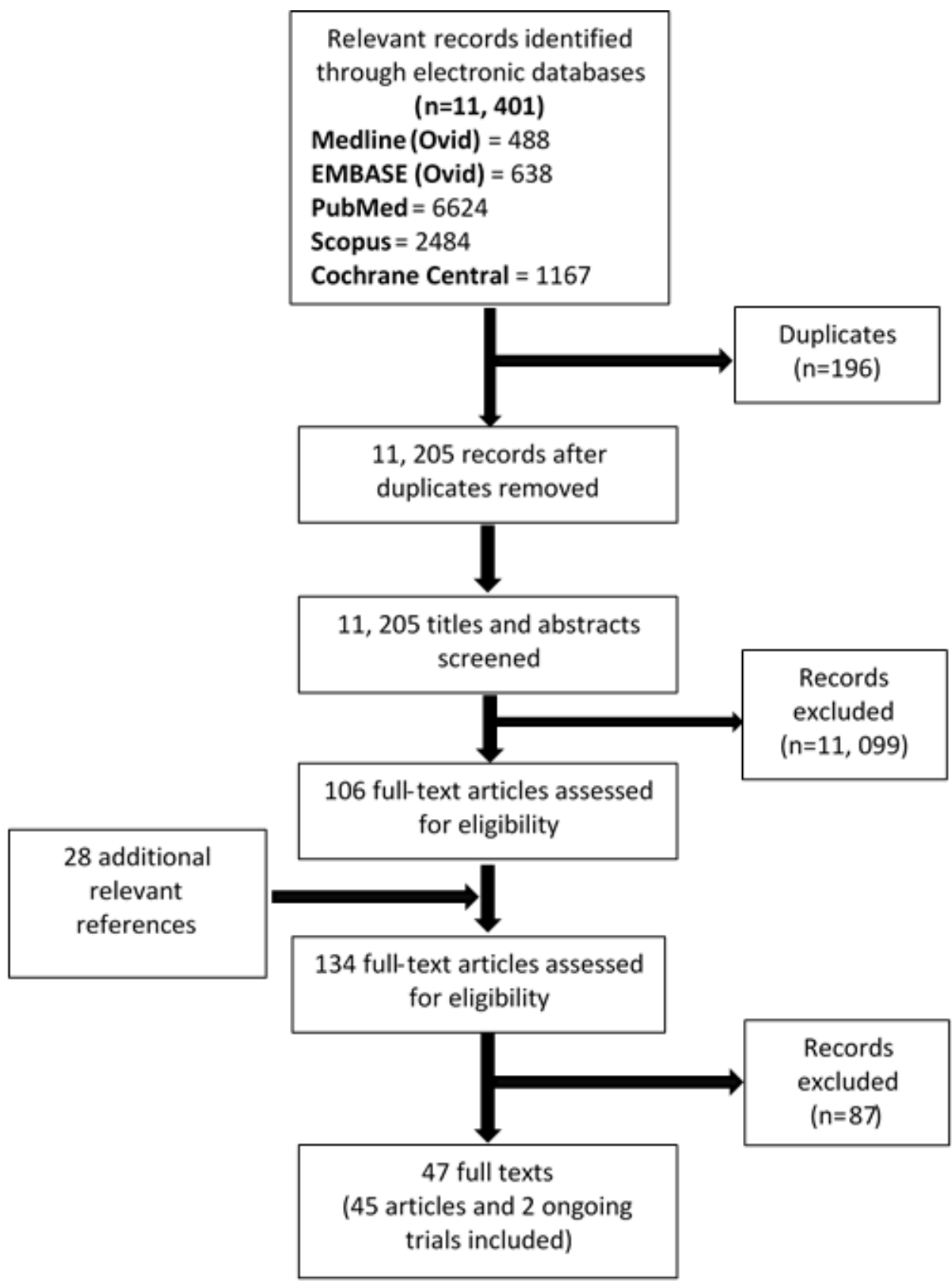

\section{Characteristics of Included Studies}

In this scoping review, 40 included studies were from high-income countries (HICs) and 6 were from low- and middle-income countries (LMICs). A total of 22 studies were from European countries, including Italy $[44,45]$, Switzerland [30,46-52], France [53,54], Portugal [55], The Netherlands [56], the United Kingdom [57-61], Spain [62,63], and Sweden [64]. Moreover, 8 studies originated from Asian countries: Philippines [65], China [66], Japan [67,68], Pakistan [69], India [70,71], and Hong Kong [72]. Other geographic regions acknowledged in the studies of this review were Australia [73,74], Canada [75], New Zealand [76,77], South Africa [78], and the United States of America [79-89].

A variety of study designs were used in the included studies, comprising 20 case studies [44,48,51,61-63,66,69,71, 73-79,82,84,85,89], 4 surveys [55,56,59,65], 3 observational studies $[53,86,87], 11$ randomized controlled trials $[46,49,50,57,64,67,72,80,81,83,88], 3$ diagnostic accuracy studies [58,60,68], 3 controlled before and after studies [30,45,70], 2 ongoing trials [51,54], and 1 pilot study [47] (Figure 3). 
Figure 3. Bubble plots showing the distribution of identified study designs, types of conversational agents and healthcare topics in the included articles, plotted against the year of the publication. The scale on the right indicates that the size of the bubble is associated with the number of studies whereby the smallest denotes 1 study and the largest, 10 studies.

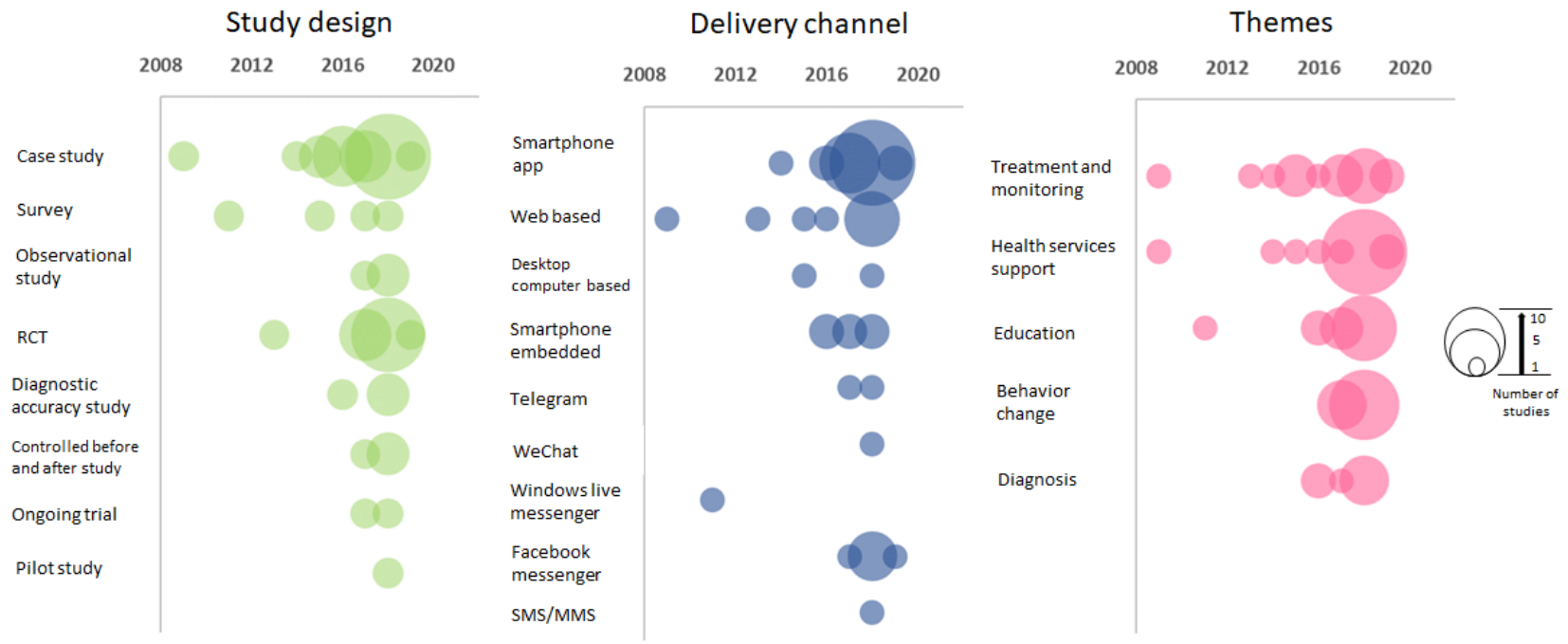

The types of literature included 25 journal articles [44,48,55-57,61-65,67,69,72,74-76,80-87,89], 11 conference abstracts $[45,47,49,50,52,59,70,71,73,78,79], 4$ conference papers [30,46,66,77], 1 poster abstract [68], 4 electronic preprints $[53,58,60,88]$, and 2 clinical trial protocols [51,54].

There was an increase in the number of publications each year, from 3 in 2015 to 5 in 2016, 10 in 2017, and 23 in 2018. Some author groups were highly productive and published at least two papers within 2 years. Kowatsch et al published 3 papers between 2017 and 2018 based on their open source behavioral intervention platform MobileCoach, which allows the authors to design a text-based health care conversational agent for obesity management and behavior change [30,46,90]. Griol et al published articles on conversational agent for chronic conditions, including chronic pulmonary disease [63] and Alzheimer disease [62] in 2015 and 2016, respectively. Such productive teams reiterate the research interest in this area of conversational agents. Furthermore, the high frequency of publication indicates the feasibility and support to conduct research successfully in this area.

\section{Characteristics of Conversational Agents in the Included Studies}

\section{Conversational Agent Delivery Channel}

Conversational agents were delivered through a variety of means in the included studies. Most $(n=23)$ were smartphone apps [30,46-50,53,55,58-61,64,67,70,71,75,77,81,83,85,86,88]; web based $(n=5)[57,66,73,74,82]$; desktop computer based $(n=2)$ $[65,79]$; used smartphone-embedded software $(n=6$; eg, Siri, Google Assistant, Alexa, etc) [44,51,62,76,84,87], Telegram [45,78], WeChat [72], SMS and multimedia messaging service [89], Windows live messenger [56], or Facebook Messenger $[52,80]$; and 4 were made available on more than 1 platform $[53,59,68,83]$. Three studies did not specify the method of conversational agent delivery $[54,63,69]$.

\section{Technical Development Approach}

A total of 8 studies made a reference to the technical details of the conversational agent development process. Some mentioned specific tools such as $\mathrm{C}$ and MS Access [65]. Others discussed the application of well-known concepts, to conversational agent development such as using the Computers are Social Actors paradigm to develop a health advice conversational agent, or converting the structure association technique (SAT) into digital SAT for implementation on a LINE platform $[67,83]$. Some emphasized data set creation and sources for the knowledge base [44]. Four studies provided an in-depth workflow with a step-by-step explanation of the technical development of the conversational agent. Cheng et al [79] provided a very detailed technical explanation of the development process - broken down and explained in parts: program development on Google's home device, webhook and internal logic, and web interface. Galescu et al [82] described the CARDIAC system architecture including a knowledge base, task models, dialogue management, speech recognition, and language generation. Griol et al [63] presented a spoken dialogue system with specific details of the proposed emotion recognizer. For example, it considers pitch, frequency, energy, and rhythm of speech input from the user. Joerin et al [75] provided a less technically dense explanation for chatbot conversational agent development but mentioned technologies used in the process, such as emotion algorithms and machine learning techniques [75].

\section{Input and Output Modalities}

The conversational agents could be categorized according to whether the user input was fixed (ie, predetermined text) or unrestricted (ie, free text/speech). A total of 10 studies employed fixed text user inputs $[30,46,47,49,50,52,54,58,83,88]$, with 2 additional studies enabling fixed text and image inputs $[67,68]$. Moreover, 19 studies allowed free text user inputs [45,48,51,56,57,60,61,66,69,70,72,74,77,78,80,81,85,86,89], and 4 studies used both fixed and free text user inputs 
$[53,64,65,73]$. Speech was enabled in 8 studies $[44,55,63,71,76,79,82,84]$, whereas free text and speech were employed in 3 studies $[62,75,87]$. The method of user input was unspecified in 1 study [59] (Multimedia Appendix 2).

Similarly, output modalities largely employed text alone $(\mathrm{n}=30)$ [45-47,49-51,53,54,56-58,60,61,64-66,68-70,72-74,77,78,80,81,83,85,88,89]; text and speech $(n=5)[48,55,63,71,87]$; speech alone $(n=4)$ $[44,79,82,84]$; text and images $(n=4)[30,67,75,86]$; text, speech, and images [62]; or text, speech, images, and videos [52,76]. The input and output methods were not specified in 1 of the studies [59] (Multimedia Appendix 2).

\section{Conversational Agent Personality}

We condensed the descriptive terms used in individual studies to present the conversational agents into a list of 9 relevant personality traits as presented in Table 1 .
The conversational agents in the included studies were health care professional like $[57,58,62,66,71,73,74,86]$, informal $[46,52,53,56,61,65,81,85]$, coach like $[47,49,52,64,66,70,80]$, knowledgeable [56,60,68,72,89], human like [48,78,79,88], culture specific $[47,48,53]$, factual $[68,76]$, gender specific $[46,78]$, and some identified explicitly as a conversational agent $[46,65]$.

One article [78] reported on a conversational agent personality that was criticized for being overly formal, and some articles did not report on the personality of the conversational agent at all $[30,44,45,50,51,54,55,59,63,67,69,75,77,82-84,87]$.

Table 1. Personality codes derived for the conversational agents included in this review, adapted from Haan et al.

Personality codes
Coach like
Conversational agent identity
Culture specific
Factual
Gender specific
Health care professional like
Human like
Informal
Knowledgeable
Human Involvement
A health care administrator or professional was available via
the conversational agent for the user to communicate with in
some studies. The role of the human varied from an
administrator who could be contacted via a dedicated chat
channel for the user to ask questions or an individual whose
role was to monitor the user's activity on the conversational
agent and provide personalized feedback to them. Seven studies
[30,46,47,70,72,78,85] reported on human involvement in the
conversation and the remaining articles did not.
(n)

\section{Conversational Agent Goals}

All the conversational agents in this review were identified as goal oriented. Goal-oriented conversational agents have a clearly defined end point and are employed to execute a specific function, unlike chit chat agents that have no specific end goal, do not delve into the details of any topic, and have a primary aim of merely keeping the conversation going [91]. Goal-oriented conversational agents were further divided into those that yielded long- or short-term outcomes. Of the included studies, 22 articles focused on conversational agents with long-term goals and 23 with short-term goals (Multimedia Descriptions

Encouraging, motivating, and nurturing

Explicitly identifies as a conversational agent

Speaks the native language or has native names

Nonjudgmental, no personal opinions, and responses based on facts or observations

Male and female versions available

Designed to be a doctor or expert, that is, mimics a health care professional

Tries to emulate humans, for example, participants reported feeling like they were talking to another human or researchers used features like "typing" to make the conversation more human like

Informal, like talking to a friend. Uses exclamations, abbreviations, and emoticons

Content created or informed by medical experts

Appendix 3 [30,44-89]). Two studies reported on conversational agents with both short-term and long-term goals [45,56], for example, answering immediate queries (short) and providing education and increasing users' knowledge on the topic over time (long) [56]. Conversational agents with short-term scope provided users with a response or service almost instantaneously, such as answering health-related queries [84]. Conversely, those with long-term scope needed to build a relationship with the user, over time, to help them overcome health-related issues such as smoking cessation [72] or working through a mental health problem [80].

\section{Conversational Agent Content Analysis}

Five distinct themes were identified in terms of conversational agent content: treatment and monitoring (ie, treatment implementation, management, adherence, support, and monitoring), health service support (ie, connecting patients to health care services), education (ie, provision of health care-related information), lifestyle behavior change (ie, supporting users in tackling various modifiable health risk factors), and diagnosis (ie, identification of the nature of a disease or a condition). A number of included conversational 
agents spanned several different themes (Multimedia Appendices 3 and 4 [30,44-89]).

\section{Treatment and Monitoring}

Overall, 17 articles reported on conversational agents that focused on treatment, monitoring, or rehabilitation of patients with specific conditions. One study reported on a conversational agent to help preserve cognitive abilities in those with Alzheimer disease [62]. Two other studies focused on conversational agents to provide support and treatment for metabolic conditions such as type 2 diabetes [70] and obesity [46]. Eight studies presented conversational agents for managing mental health using techniques such as counseling [67]; cognitive behavioral therapy (CBT) [64,80] method of levels therapy [57]; positive psychology [61]; provision of a virtual companion [66]; and a combination of modalities such as CBT with mindfulness-based therapy, emotionally focused therapy, and motivational interviewing $[75,81]$. One study each reported on the use of a conversational agent for monitoring patients with asthma [85], HIV [45], heart failure [82], and chronic respiratory disease management [63]. Non-disease-specific conversational agents were used as a health information advisor [83] and pediatric generic medicine consultant [65].

\section{Health Care Services Support}

Overall, 19 studies reported on conversational agents used to support or complement existing health care services. These tasks included remote delivery of health care services for mental health support [67,75,81], breast cancer [53,54], dysarthria [44], obesity [50], diabetes management [79], chronic respiratory diseases [63], asthma [85], heart failure [82], and HIV management [45]. Other studies discussed conversational agents automating health care services such as patient history taking [48,77], providing health advice [83], symptom checking [58], and triaging and diagnosis support $[60,69,74]$.

\section{Education}

We found 13 articles in which conversational agents were used primarily for educating patients or users. Education focused on topics such as sexual health $[59,76]$ including information on HIV [78], overcoming unhealthy habits such as alcohol misuse [73] and smoking cessation [72], improving well-being [88], diabetes management [79], breast cancer [53,54], and medication-related queries [55] as well as general health [56,84,87], which covered more than 1 topic of focus, for example, education on sex, drugs, and alcohol for adolescents.

\section{Lifestyle Behavioral Changes}

We identified 12 studies with conversational agents for healthy lifestyle behavior change in the general population as well as overweight and obese individuals. Two studies discussed conversational agents for the management of obesity in younger patients, including adolescents $[46,50]$. They largely employed a coach-like conversational agent to promote physical activity [51] and healthy eating [52], sometimes with incentive provision, and provided techniques on how to reverse obesity $[30,47,49,71]$. Other behavioral change interventions used a social media-driven conversational agent for smoking cessation [72], a health coach for diabetes prevention [86], a reflection companion to encourage physical activity in adults [89], and emotionally intelligent agents to improve mental health [61] and well-being [88].

\section{Diagnosis}

Seven articles presented health care conversational agents with a primary purpose of establishing a diagnosis. Three articles reported on conversational agents' triage, diagnosis, or a combination of both, mainly employing a symptom checker function $[58,60,74]$. Three more studies reported purely on the diagnostic accuracy of 2 conversational agents [69,71,77]. One article reported on a conversational agent for diagnosing sexually transmitted infections to overcome barriers such as social stigma, embarrassment, and discomfort associated with traditional diagnostic approaches that require a medical interview with a health care professional [68].

\section{Conversational Agent Evaluation}

Included studies that evaluated conversational agents reported on their accuracy (in terms of information retrieval, diagnosis, and triaging), user acceptability, and effectiveness. Some studies reported on more than 1 outcome, for example, acceptability and effectiveness. In general, evaluation data were mostly positive, with a few studies reporting the shortcomings of the conversational agent or technical issues experienced by users. Seventeen studies presented self-reported data from participants in the form of surveys, questionnaires, etc. In 16 studies, the data were objectively assessed in the form of changes in BMI, number of user interactions, etc. In 12 studies, there was a mixture of self-reported and objectively assessed outcomes and outcomes were not reported in the two ongoing trials (Multimedia Appendix 4).

\section{Accuracy: Information, Diagnosis, and Triaging}

Eleven studies reported on the accuracy of conversational agents [44,58,60,66,68,69,71,74,76,77,82] (Multimedia Appendix 4). Middleton et al [58] and Razzaki et al [60] evaluated 2 versions of the Babylon conversational agent, respectively: Babylon check and Babylon chatbot for triage and diagnosis. In both studies, the conversational agents were tested on their triage and diagnostic accuracy using clinical vignettes as in the Membership of the Royal College of General Practitioners exams, and their performance was compared with that of doctors. The conversational agents were found to be more accurate, faster, and provided safer triage and diagnosis compared with doctors and nurses. Similarly, Ghosh et al [74] and Danda et al [71] assessed conversational agents on their general diagnostic accuracy, and these had a precision rate of $82 \%$ and $86 \%$, respectively. $\mathrm{Ni}$ et al [77] assessed Chatbot MANDY, designed to automate patient intake, on its ability to adequately diagnose the patient based on their symptoms. There was a prediction accuracy of $100 \%, 64 \%, 25 \%$, and $14 \%$ for respiratory issues, chest pain, headache, and dizziness, respectively [77]. Furthermore, 2 studies tested the accuracy of conversational agents employed for sexual health purposes $[68,76]$. The conversational agent used by Kobori et al [68] diagnosed sexually transmitted infections with an accuracy of $77.7 \%$ and had high effectiveness $(97.7 \%)$ in encouraging patients to visit the clinic earlier. In contrast, Wilson et al [76] compared smart assistants-Google Assistant, Siri, and Google 
search - to determine their accuracy in responding to queries around sexual health. The Google search option was found to provide the best answers and also had the lowest failure rate [76]. Another study compared 3 known virtual assistants-Siri, Google Assistant, and Amazon Alexa-on their abilities to recognize speech from individuals with dysarthria [44]. They all performed similarly (50-60\% recognition), with Siri being the only agent attempting to parse all the dialogue inputted [44]. Two studies discussed the accuracy of 2 conversational agents in making diagnoses in children and adolescents $[66,69]$. Teenchat had a 78.34\% precision rate in diagnosing stress [66], whereas Aquabot had an accuracy of $85 \%, 86.64 \%$, and $87.2 \%$ (3 groups aged 18-28 years) for achluophobia and 88\%, 87.6\%, and $87.53 \%$ (3 patient groups aged 1-7 years) for autism [69]. Finally, Galescu et al [82] discussed the accuracy of a conversational agent CARDIAC in speech recognition for heart failure patients. A significant number of errors were detected and attributed to insufficient vocabulary coverage in the language model as evidenced by an out-of-vocab rate of $3 \%$ [82].

\section{Effectiveness}

The effectiveness of health care conversational agents was assessed in 8 studies $[47,52,57,61,70,75,81,84]$. Furthermore, 10 studies reported on the effectiveness and acceptability, of which 5 are presented here $[49,64,67,80,86]$ and the remainder are presented under Acceptability (Multimedia Appendix 4). Five studies described conversational agents targeting a healthy lifestyle change specifically for healthy eating [52], active lifestyle [49], obesity [47], and diabetes management [70,86] Casas et al [52] reported improvements in food consumption, whereas Stasinaki [47] and Heldt et al [49] noted increases in physical activity performance with high compliance. Shaikh et al [70] reported successful reduction in $\mathrm{HbA}_{1 \mathrm{c}}$ (glycated hemoglobin) levels postengagement with Wellthy diabetes, whereas Stein et al [86] reported successful weight loss (2.38\%) and satisfaction was high, rated at $87 \%$ for the diabetes prevention chatbot.

Eight studies noted the effectiveness of conversational agents for mental health applications $[57,61,64,67,75,80,81,84]$. The conversational agent Tess by Fulmer et al [81] initiated a statistically significant improvement in depression and anxiety compared with the control group. Two studies looked at the use of machine learning-based conversational agents for CBT in young adults $[64,80]$. The conversational agent was both effective (reduced levels of depression and perceived stress and improved psychological well-being) and well received (high engagement with the chat app and high levels of satisfaction) $[64,80]$. This positive effect was reproduced by Joerin et al [75], where emotional support from Tess decreased symptoms of anxiety and depression by $18 \%$ and $13 \%$, respectively [75]. Inkster et al [61] employed the Patient Health Questionnaire-9 self-reported depression scale to note significant improvements in depression scores in the high user group compared with the low user group [61]. In addition, $67.7 \%$ of users found the app usage to be helpful and encouraging [61]. In the study by Kamita et al [67], the counseling bot encouraged significant improvements in users' self-esteem, anxiety, and depression compared with the control condition. Besides effectiveness, user ratings of acceptability, using the technology acceptance model, were higher in the conversational agent condition compared with the control [67]. Gaffney et al [57] proposed a conversational agent $M Y L O$ that was significantly better than the existing conversational agent ELIZA in problem solving and helpfulness, but both were equally effective in lowering distress. Miner et al [84] compared Apple's Siri, Microsoft's Cortana, Samsung's S Voice, and Google Now on their abilities to respond to questions about mental health, interpersonal violence, and physical health. Siri responded appropriately and empathetically to issues concerning depression and physical health, and Cortana responded appropriately and empathetically to matters involving interpersonal violence [84].

\section{Acceptability}

A total of 26 studies commented on the acceptability of conversational agents (Multimedia Appendix 4). Five studies commenting on acceptability and effectiveness were discussed above $[49,64,67,80,86]$ (see the Effectiveness section), and the remaining 21 studies are presented here $[30,45,46,48,50,53,55,56,59,62,63,65,72,73,78,79,83,85,87-89]$. Several studies $(n=6)$ were targeted at children or adolescents. Three studies discussed conversational agents for health education on medication, asthma management, drugs, sex, and alcohol $[56,65,85]$. Acceptability was generally denoted by high response rates and scores like strongly agree or agree for user-friendliness, appropriateness, consistency, and speed of response [65]. In addition, users in the study by Crutzen et al [56] favored the conversational agent over existing methods of information provision. In another 3 studies, conversational agents were employed for the management of obesity in adolescents [30,46,50]. Acceptability was high in all studies, as evidenced by enjoyment of the chats; bonding; formation of social and emotional relationships; and high perceived ease of use, usefulness, and intention to use [30,46,50]. In the study by L'Allemand et al [50], high compliance was attributed to the rewarding game system.

In 4 studies, health care conversational agents were targeted at chronic conditions $[55,62,63,79]$. The specific conditions addressed were Alzheimer disease, diabetes, heart failure, and chronic respiratory disease. In the study by Cheng et al [79], users responded positively, particularly to features of conversational agents that allowed for personalization and the conversational agent's ability to understand and respond to natural conversation flow. Some difficulties included learning commands, restricted answer options, slow processing speed, and some problematic responses [79]. Lobo et al [55] reported user acceptability in the form of usability, where the conversational agent had a system usability score of 88 , which was considered very good. Griol et al [62] considered the Alzheimer patients' caregiver's perspective when judging the acceptability of the conversational agent. The global rate for the system (on a scale from 0 to 10 ) was 8.6, and the application was thought to be attractive, adequate, and appropriate for its purpose. In another study, Griol et al [63] employed an emotionally sensitive conversational agent for chronic respiratory disease patients who rated this agent significantly higher for interaction rate, frequency, and empathy than the baseline version. 
A further 3 studies were concerned with sexual health and/or HIV management $[45,59,78]$. They indicated that in this field, conversational agents could be used for a variety of functions such as booking an appointment, getting test results, therapy, and event reminders [45]. In addition, the conversational agent in the study by van Heerden et al [78] was well received when used as a counseling tool because it was given an avatar-like profile image and the conversation was embedded in a familiar chat interface, which users associated with talking to another human being. In the study by Nadarzynski et al [59], users favored the conversational agent because of its ubiquity as a convenient smartphone app and its ability to perform remote services such as video consultation, potentially alleviating any inhibitions users may have around discussing sexual health in person.

Two studies employed an emotionally sensitive conversational agent for mental health counselling and general health information advice $[83,88]$. In the study by Liu et al [83], the sympathetic conversational agent was rated more positively than the advice-only condition. Another conversational agent for well-being improvement procured positive feedback from participants who thought it was an interesting experience, pretty quick, and fun [88].

In 3 studies, conversational agents were used for healthy behavior change, specifically targeting smoking cessation, alcohol misuse treatment, and physical activity promotion $[72,73,89]$. For smoking cessation, participants indicated enjoyment when conversing with the conversational agent, and effectiveness was also insinuated by $38.3 \%$ reporting not having smoked in the past week and $69.4 \%$ admitting to a reduction in smoking frequency [72]. In the study by Elmasri et al [73], the participants (young adults) reported a higher satisfaction rate with the use of the conversational agent to manage and treat alcohol misuse. For physical activity promotion through the use of a reflection companion, response rates were high $(96 \%$ at baseline, $90 \%$ at follow-up), insinuating high engagement throughout the study. Furthermore, use of the system beyond the stipulated study period was an indicator of viability. Moreover, 16 of the 33 participants opted to continue without any reward, suggesting participants found some added value in using the conversational system [89].

Two studies examined the acceptability of conversational agents for health care service delivery $[48,87]$. Outcomes were reported qualitatively, including comments on ease of use, humanity of the chatbot, and users' comfort with the input functionalities available to them as well as criticisms on technical difficulties [48]. Bickmore et al [87] more specifically compared conversational assistants Siri, Alexa, and Google Assistant on their provision of health information and found satisfaction to be lowest with Alexa and highest with Siri. Overall, there was a neutral rating for satisfaction, with a median score of 4 (IQR 1-6) [87].

One study discussed a condition-specific conversational agent application targeted at improving the quality of life and medication adherence of breast cancer patients [53]. Participants implied a positive experience when interacting with the conversational agent, whereby $88 \%$ said it provided them with support in tracking their treatment and mentioned that they would recommend the conversational agent to their friends. There was an overall satisfaction of 94\% [53].

\section{Discussion}

\section{Principal Findings}

Our scoping review identified 45 studies and 2 ongoing clinical trials. Although conversational agents have been widely employed in various fields, their use in health care is still in its infancy, as evidenced by the study findings that indicate much of the literature being published recently (2016-2018). Most conversational agents used text input and were machine learning based and mobile app delivered. The 3 most commonly reported themes in the health care conversational agent-related literature were treatment and monitoring, health services support, and patient education. Results from the studies evaluating conversational agents were generally positive, reporting effectiveness, accuracy, and acceptability of the conversational agent. However, there is currently a dearth of robust evaluations and a predominance of small case studies.

Our review shows that most of the health care conversational agents reported in the literature used machine learning and were long-term goal oriented. This suggests that conversational agents are evolving from conducting simple transactional tasks toward more involved end points such as long-term disease management [80] and behavior change [30]. The majority of the conversational agents identified in this review targeted patients, with only a few aimed at health care professionals, for example, by automating patient intake or aiding in patient triage and diagnosis. In addition, research into the use of conversational agents to support both formal and informal caregivers is limited and could be a productive area to explore, given that previous systematic reviews on the use of digital technology for caregivers of patients with psychosis [92] or dementia [93] have shown positive outcomes.

Our findings show a predominance of text-based conversational agents, with only a few apps using speech as the main mode of communication. Yet, certain populations, such as older people, may be more comfortable interacting via speech, as some individuals may find the dexterity involved with typing on small keypads on smartphones challenging and time consuming. Furthermore, most conversational agents included in our review were app based. Research shows that the use of apps (which need to be downloaded and regularly updated) is often associated with high dropout rates and low utilization [94]. Such disadvantages do not seem to apply to messaging apps such as Facebook Messenger, iMessage, Telegram, WeChat, or WhatsApp, which are already commonly used in the general population. Future research should aim to overcome this limitation brought on by smartphone apps by embedding future health care conversational agents in platforms, which the target population already uses regularly. The advantage of having numerous publishing platform options is the novelty of conversational agents over smartphone apps, and this should be further explored. 
A recent systematic review on the effectiveness of ECAs and other conversational agents noted a lack of an established method for evaluating health care conversational agents in health care and a dearth of data on adverse effects [32]. This corresponds to our findings, with most studies being case studies and lacking information on potential adverse effects. Side effects to consider may relate to the content of the conversational agent conversations, which may not be accurate, evidence based, or suitable for the specific circumstance. For example, if a mental health conversational agent user has suicidal tendencies, the conversational agent may not be best equipped to handle such a situation and may provide inappropriate advice, leaving the user at fatal risk. Additional unwanted effects could arise from the black box effect associated with the use of machine learning-based conversational agents, whereby their suggestions are somewhat unpredictable [95]. Furthermore, conversational agents allowing for free text input may lead to significant privacy concerns, especially for vulnerable populations, as individuals can share private and sensitive data in conversations [96]. There is a need for stringent certification from a regulatory board in cases where conversational agents are given roles akin to health care professionals.

The health care sectors for conversational agent application identified in the review were generally very broad, with references to only a few specialties including mental health [97], neurodegeneration [62], metabolic medicine (obesity [47] and diabetes [70,79]), and sexual health [68]. Future applications could expand toward other health care fields where evidence has suggested potential for digital health interventions such as dermatology [98], primary care [99], geriatrics [100], and oncology [101].

There is also a need for more geographically diverse research. Although our review identified 12 articles with a geographical focus in Asia, the evidence stemming from middle-income countries was scarce, and there were no studies from a low-income country. However, digital health initiatives are becoming more common in developing countries, often with a different, context-specific scope, such as ensuring access to health care using social media [102]. To ensure safe and effective use of solutions developed in HIC settings, there is a need for more research to corroborate the safety, effectiveness, and acceptability of these agents in LMICs too. Furthermore, it is important to explore the integration of conversational agents into the existing health systems and services. A hybrid system, where digital technology supplements health care services, is increasingly seen as the optimal solution [103]. This mirrors our acknowledgment that conversational agents will be most advantageous in supporting rather than substituting health care professionals. In most studies, conversational agents were developed and presented independently, unsupported by humans, and separate from the existing health care delivery models, which may prove unsustainable in the long run. Future research should consider evaluating hybrid systems encompassing conversational agents in their health care delivery, as reported in some of the included studies where conversational agents were complemented by frequent meetings and phone calls with the physicians.

Although the studies reported accuracy, efficacy, effectiveness, and acceptability as outcomes, there were no measurements of cost, efficiency, or how the solution led to improved productivity when used instead of or to augment the work of a health professional. Therefore, it was not possible to ascertain whether the solutions developed were cost-effective compared with alternative approaches.

\section{Strengths and Limitations}

We conducted a comprehensive literature search of multiple databases, including gray literature sources. We prioritized sensitivity over specificity in our search strategy to capture a holistic representation of conversational agent usage uptake in health care. However, given the novelty of the field and the employed terminology, some unpublished studies discussed at niche conferences or meetings may have been omitted. Furthermore, although classification of the themes of our conversational agents was based on thorough analysis, team discussions, and consensus, it might not be all inclusive and may require further development with the advent of new conversational agents. In addition, although some conversational agents belong to more than 1 theme, we mostly classified them based on the dominant mode of application for the sake of clarity. Finally, we excluded articles with poorly reported data on chatbot assessments; therefore, we may have missed some health care conversational agents (Multimedia Appendix 5 [36,97,104-188]). We decided to exclude these because they did not appear to contribute anything additional or noteworthy to our review. The personality traits presented were guided by a reference paper on chatbot personality assignment [43] and also a condensation of descriptive terms from several articles. The lack of depth and breadth in the description of the content and development of many conversational agents led us to organically develop a framework for this paper. This framework is, therefore, still exploratory and adapted to suit the purposes of this review and may well be explored and further refined with more in-depth analysis such as previously published frameworks [189].

\section{Conclusions}

Conversational agents are an up-and-coming form of technology to be used in health care, which has yet to be robustly assessed. Most conversational agents reported in the literature to date are text based, machine learning driven, and mobile app delivered. Future research should focus on assessing the feasibility, acceptability, safety, and effectiveness of diverse conversational agent formats aligned with the target population's needs and preferences. There is also a need for clearer guidance on health care -related conversational agents' development and evaluation and further exploration on the role of conversational agents within existing health systems. 


\section{Acknowledgments}

This research is supported by the Ageing Research Institute for Society and Education (ARISE), Nanyang Technological University, Singapore. This study is also supported by the National Research Foundation, Prime Minister's Office, Singapore under its Campus for Research Excellence and Technological Enterprise (CREATE) program.

\section{Authors' Contributions}

LTC conceived the idea for this study. DD, BK, and LC screened the articles. DD, BK, and LC extracted and analyzed the data. DD and LC wrote the manuscript. BK, TK, JR, RA, and YLT revised the manuscript critically.

\section{Conflicts of Interest}

TK is affiliated with the Center for Digital Health Interventions, a joint initiative of the Department of Management, Technology, and Economics at ETH Zurich and the Institute of Technology Management at the University of St. Gallen, which is funded in part by the Swiss health insurer CSS. TK is also a cofounder of Pathmate Technologies, a university spin-off company that creates and delivers digital clinical pathways. Other authors declare that they have no competing interests.

\section{Multimedia Appendix 1}

Search strategy.

[DOCX File , 18 KB-Multimedia Appendix 1]

\section{Multimedia Appendix 2}

Types of user input (blue) and output (green) in the conversational agents.

[DOCX File, 32 KB-Multimedia Appendix 2]

\section{Multimedia Appendix 3}

Characteristics of conversational agents reported in the included studies.

[DOCX File , 44 KB-Multimedia Appendix 3]

\section{Multimedia Appendix 4}

Characteristics of included studies.

[DOCX File , 45 KB-Multimedia Appendix 4]

\section{Multimedia Appendix 5}

List of excluded studies and reasons for exclusion.

[DOCX File, 30 KB-Multimedia Appendix 5]

\section{References}

1. Chatbot. Oxford Living Dictionaries. 1990. URL: https://en.oxforddictionaries.com/definition/chatbot [accessed 2020-07-18]

2. Veretskaya O. What is a Chatbot and How to Use It for Your Business. Medium. 2017. URL: https://medium.com/swlh/ what-is-a-chatbot-and-how-to-use-it-for-your-business-976ec2e0a99f [accessed 2020-07-18]

3. Smart Speaker Sales More Than Tripled in 2017. Billboard. 2017. URL: https://www.billboard.com/articles/business/ 8085524/smart-speaker-sales-tripled-25-million-year-2017 [accessed 2020-07-18]

4. Perez S. 39 Million Americans Now Own a Smart Speaker, Report Claims. Tech Crunch. 2018. URL: https://techcrunch. com/2018/01/12/39-million-americans-now-own-a-smart-speaker-report-claims/ [accessed 2020-07-18]

5. Smart Speakers 2018: World Market Forecast to 2023 - Key Vendors Covered include Alphabet, Amazon, Harman Intl, Alibaba and Sonos. Cision PR Newswire. 2018. URL: https://www.prnewswire.com/news-releases/ smart-speakers-2018-world-market-forecast-to-2023--key-vendors-covered-include-alphabet-amazon-harman-intl-alibaba-and-sonos-300676460. $\underline{\mathrm{html}}$ [accessed 2020-07-18]

6. Saeed H. Developing a Chatbot? Learn the Difference between AI, Machine Learning, and NLP. Chatbots Life. 2016. URL: https://chatbotslife.com/developing-a-chatbot-learn-the-difference-between-ai-machine-learning-and-nlp-40a3f745aec4 [accessed 2020-07-18]

7. Seeman P. Natural language generation: an overview. J Comput Sci Res 2012;1(3):50-57 [FREE Full text] [doi: 10.1093/oxfordhb/9780199276349.013.0015]

8. What is a Chatbot? All You Need to Know About Chatbots!. Botpress: Open-Source Conversational AI Platform. 2018. URL: https://botpress.io/learn/what-and-why/ [accessed 2020-07-18] [WebCite Cache ID 746pXZ3d7] 
9. Understanding the 'Black Box' of Artificial Intelligence. Reddit. 2018. URL: https://www.reddit.com/r/artificial/comments/ 9iapbc/understanding the black box of artificial/ [accessed 2020-07-18] [WebCite Cache ID 746puKdDT]

10. Lewis C, Monnet D. AI and Machine Learning Black Boxes: The Need for Transparency and Accountability. KDnuggets News. 2017. URL: https://www.kdnuggets.com/2017/04/ai-machine-learning-black-boxes-transparency-accountability. $\underline{\mathrm{html}}$ [accessed 2020-07-18]

11. Holm EA. In defense of the black box. Science 2019 Apr 5;364(6435):26-27. [doi: 10.1126/science.aax0162] [Medline: 30948538]

12. Weizenbaum J. ELIZA---a computer program for the study of natural language communication between man and machine. Commun ACM 2012;9(1):36-45. [doi: 10.1145/365153.365168]

13. Deryugina OV. Chatterbots. Sci Tech Inf Proc 2010 Sep 5;37(2):143-147. [doi: 10.3103/s0147688210020097]

14. The History of Chatbots. Futurism: Science and Technology News and Videos. 2016. URL: https://futurism.com/images/ the-history-of-chatbots-infographic/ [accessed 2020-07-21]

15. Colby K. Artificial Paranoia: A Computer Simulation of Paranoid Processes. New York, USA: Elsevier; 2013.

16. McTear M, Callejas Z, Griol D. The Conversational Interface: Talking to Smart Devices. Switzerland: Springer International Publishing; 2016.

17. Rose Medical Center. Letting fingers do the talking. Computer makes patient satisfaction surveys a snap. Rose Medical Center, Denver, CO. Profiles Healthc Mark 1992(48):40-44. [Medline: 10120010]

18. Delichatsios HK, Friedman RH, Glanz K, Tennstedt S, Smigelski C, Pinto BM, et al. Randomized trial of a 'talking computer' to improve adults' eating habits. Am J Health Promot 2001;15(4):215-224. [doi: 10.4278/0890-1171-15.4.215] [Medline: $\underline{11349340]}$

19. Friedman E. Your friendly neighborhood diagnosis-aiding talking computer. Hospitals 1981 Oct 16;55(20):105-6, 108, 113. [Medline: 7275074$]$

20. Friedman RB, Newsom RS, Entine SM, Cheung S, Schultz JV. A simulated patient-physician encounter using a talking computer. J Am Med Assoc 1977 Oct 31;238(18):1927-1929. [Medline: 578551]

21. Migneault JP, Farzanfar R, Wright JA, Friedman RH. How to write health dialog for a talking computer. J Biomed Inform 2006 Oct;39(5):468-481 [FREE Full text] [doi: 10.1016/j.jbi.2006.02.009] [Medline: 16564749]

22. Mayo J. 2016: The Year When Chatbots Were Hot. Chatbots Life. 2016. URL: https://chatbotslife.com/ 2016-the-year-when-chatbots-were-hot-3d61046527f9 [accessed 2020-07-18]

23. Bruner J. Why 2016 is Shaping Up to Be the Year of the Bot. O'Reilly Media Inc. 2016. URL: https://www.oreilly.com/ ideas/why-2016-is-shaping-up-to-be-the-year-of-the-bot [accessed 2020-07-18]

24. Goebel T. 2016 - The Year of the Chatbot. Aspect Blog. 2016. URL: https://blogs.aspect.com/2016-the-year-of-the-chatbot/ [accessed 2020-07-18]

25. Stormon A. The Uncomfortable Truth About Bots: 3 Reasons Why They're Failing Miserably. Chatbots Magazine. 2017. URL: https://chatbotsmagazine.com/3-uncomfortable-reasons-why-chatbots-are-failing-8913901a29e5 [accessed 2020-07-18]

26. Prize L. Mitsuku Wins 2019 Loebner Prize and Best Overall Chatbot at AISB X. AISB - The Society for the Study of Artificial Intelligence and Simulation of Behaviour. 2019. URL: https://aisb.org.uk/new site/?p=350 [accessed 2020-07-18]

27. Neville R, Greene A, McLeod J, Tracey A, Tracy A, Surie J. Mobile phone text messaging can help young people manage asthma. Br Med J 2002 Sep 14;325(7364):600 [FREE Full text] [doi: 10.1136/bmj.325.7364.600/a] [Medline: 12228151$]$

28. Hall AK, Cole-Lewis H, Bernhardt JM. Mobile text messaging for health: a systematic review of reviews. Annu Rev Public Health 2015 Mar 18;36:393-415 [FREE Full text] [doi: 10.1146/annurev-publhealth-031914-122855] [Medline: 25785892]

29. Rathbone AL, Prescott J. The use of mobile apps and SMS messaging as physical and mental health interventions: systematic review. J Med Internet Res 2017 Aug 24;19(8):e295 [FREE Full text] [doi: 10.2196/jmir.7740] [Medline: 28838887]

30. Kowatsch T, Volland D, Shih I, Rüegger D, Künzler F, Barata F. Design and Evaluation of a Mobile Chat App for the Open Source Behavioral Health Intervention Platform MobileCoach. In: Chatbots International Conference on Design Science Research in Information System and Technology. 2017 Presented at: DESRIST 2017; May 30-June 1, 2017; Karlsruhe, Germany. [doi: 10.1007/978-3-319-59144-5_36]

31. Tropea P, Schlieter H, Sterpi I, Judica E, Gand K, Caprino M, et al. Rehabilitation, the great absentee of virtual coaching in medical care: scoping review. J Med Internet Res 2019 Oct 1;21(10):e12805 [FREE Full text] [doi: 10.2196/12805] [Medline: 31573902]

32. Laranjo L, Dunn AG, Tong HL, Kocaballi AB, Chen J, Bashir R, et al. Conversational agents in healthcare: a systematic review. J Am Med Inform Assoc 2018 Sep 1;25(9):1248-1258 [FREE Full text] [doi: 10.1093/jamia/ocy072] [Medline: 30010941]

33. Kocaballi AB, Berkovsky S, Quiroz JC, Laranjo L, Tong HL, Rezazadegan D, et al. The personalization of conversational agents in health care: systematic review. J Med Internet Res 2019 Nov 7;21(11):e15360 [FREE Full text] [doi: 10.2196/15360] [Medline: 31697237]

34. Provoost S, Lau HM, Ruwaard J, Riper H. Embodied conversational agents in clinical psychology: a scoping review. J Med Internet Res 2017 May 9;19(5):e151 [FREE Full text] [doi: 10.2196/jmir.6553] [Medline: 28487267]

35. Pereira J, Díaz O. Using health chatbots for behavior change: a mapping study. J Med Syst 2019 Apr 4;43(5):135. [doi: 10.1007/s10916-019-1237-1] [Medline: $\underline{\text { 30949846] }}$ 
36. Hoermann S, McCabe KL, Milne DN, Calvo RA. Application of synchronous text-based dialogue systems in mental health interventions: systematic review. J Med Internet Res 2017 Jul 21;19(8):e267 [FREE Full text] [doi: 10.2196/jmir.7023] [Medline: 28784594]

37. Vaidyam AN, Wisniewski H, Halamka JD, Kashavan MS, Torous JB. Chatbots and conversational agents in mental health: a review of the psychiatric landscape. Can J Psychiatry 2019 Jul;64(7):456-464 [FREE Full text] [doi:

10.1177/0706743719828977] [Medline: 30897957]

38. Montenegro J, da Costa CA, da Rosa Righi R. Survey of conversational agents in health. Expert Syst Appl 2019 Sep 7;129(11):56-67. [doi: 10.1016/j.eswa.2019.03.054]

39. Xing Z, Yu F, Du J, Walker JS, Paulson CB, Mani NS, et al. Conversational interfaces for health: bibliometric analysis of grants, publications, and patents. J Med Internet Res 2019 Nov 18;21(11):e14672 [FREE Full text] [doi: 10.2196/14672] [Medline: 31738171$]$

40. Peters MD, Godfrey CM, Khalil H, McInerney P, Parker D, Soares CB. Guidance for conducting systematic scoping reviews. Int J Evid Based Healthc 2015 Sep;13(3):141-146. [doi: 10.1097/XEB.0000000000000050] [Medline: 26134548]

41. Embodied Conversational Agent. Chatbots. URL: https://www.chatbots.org/embodied conversational agent/ [accessed 2020-07-18]

42. Bickmore T. Relational Agents. Northeastern University. URL: http://www.ccs.neu.edu/home/bickmore/agents/ [accessed 2020-07-18]

43. de Haan H, Snijder J, van Nimwegen C, Beun R. Chatbot Personality and Customer Satisfaction. Info Support Research. 2018. URL: https://research.infosupport.com/wp-content/uploads/

Chatbot-Personality-and-Customer-Satisfaction-Bachelor-Thesis-Information-Sciences-Hayco-de-Haan.pdf [accessed 2020-07-18]

44. Ballati F, Corno F, de Russis L. 'Hey Siri, do you understand me?': Virtual Assistants and Dysarthria. In: 7th International Workshop on the Reliability of Intelligent Environments. 2018 Presented at: WoRIE'18; June 25-28, 2018; Rome, Italy URL: https://www.researchgate.net/publication/ 325466714_Hey_Siri_do_you_understand_me_Virtual_Assistants_and_Dysarthria

45. Vita S, Marocco R, Pozzetto I, Morlino G, Vigilante E, Palmacci V. The 'doctor apollo' chatbot: a digital health tool to improve engagement of people living with HIV. J Int AIDS Soc 2018 Oct;21(Suppl 8):e25187 [FREE Full text] [doi: 10.1002/jia2.25187] [Medline: 30362663]

46. Kowatsch T, Nißen M, Shih C, Rüegger D, Volland D, Filler A. Text-Based Healthcare Chatbots Supporting Patient and Health Professional Teams: Preliminary Results of a Randomized Controlled Trial on Childhood Obesity. In: 17th International Conference on Intelligent Virtual Agents. 2017 Presented at: IVA'17; August 27-30, 2017; Stockholm, Sweden URL: https://tinyurl.com/yxpmarws

47. Stasinaki A, Brogle B, Buchter D, Shih CHI, Heldt K, White C, et al. A novel digital health intervention improves physical performance in obese youth. Swiss Medical Weekly 2018 May;148:10s-10s [FREE Full text]

48. Denecke K, Hochreutener SL, Pöpel A, May R. Self-anamnesis with a conversational user interface: concept and usability study. Methods Inf Med 2018 Nov;57(5-06):243-252. [doi: 10.1055/s-0038-1675822] [Medline: 30875703]

49. Heldt K, Buchter D, Brogle B, Shih C, Ruegger D, Filler A. Telemedicine therapy for overweight adolescents: first results of a novel smartphone app intervention using a behavioural health platform. Obesity Facts 2018 May 11(Suppl 1):214-215 [FREE Full text]

50. L'Allemand D, Shih C, Heldt K, Buchter D, Brogle B, Ruegger D. Design and interim evaluation of a smartphone app for overweight adolescents using a behavioural health intervention platform. Obesity Reviews 2018 Dec 19(Suppl 1):102.

51. Can a smartphone app that includes a chatbot-based coaching and incentives increase physical activity in healthy adults? Clinical Trials. 2017. URL: https://clinicaltrials.gov/ct2/show/NCT03384550 [accessed 2020-07-18]

52. Casas J, Mugellini E, Abou Khaled O. Food Diary Coaching Chatbot. In: Proceedings of the 2018 ACM International Joint Conference and 2018 International Symposium on Pervasive and Ubiquitous Computing and Wearable Computers. 2018 Presented at: UbiComp'18; October 8-12, 2018; Singapore p. 1676-1680. [doi: 10.1145/3267305.3274191]

53. Chaix B, Bibault JE, Pienkowski A, Delamon G, Guillemassé A, Nectoux P, et al. When chatbots meet patients: one-year prospective study of conversations between patients with breast cancer and a chatbot. JMIR Cancer 2019 May 2;5(1):e12856 [FREE Full text] [doi: 10.2196/12856] [Medline: 31045505]

54. Artificial Intelligence vs Physicians for Breast Cancer Patients' Information. Clinical Trials. 2018. URL: https://clinicaltrials. gov/ct2/show/NCT03556813 [accessed 2018-07-18]

55. Lobo J, Ferreira L, Ferreira A. CARMIE: a conversational medication assistant for heart failure. Int J E-Health Med Commun 2017;8(4):21-37. [doi: 10.4018/ijehmc.2017100102]

56. Crutzen R, Peters GJ, Portugal SD, Fisser EM, Grolleman JJ. An artificially intelligent chat agent that answers adolescents' questions related to sex, drugs, and alcohol: an exploratory study. J Adolesc Health 2011 May;48(5):514-519. [doi: 10.1016/j.jadohealth.2010.09.002] [Medline: 21501812]

57. Gaffney H, Mansell W, Edwards R, Wright J. Manage Your Life Online (MYLO): a pilot trial of a conversational computer-based intervention for problem solving in a student sample. Behav Cogn Psychother 2014 Nov;42(6):731-746. [doi: 10.1017/S135246581300060X] [Medline: 23899405] 
58. Middleton K, Butt M, Hammerla N, Hamblin S, Mehta K, Parsa A. Sorting out symptoms: design and evaluation of the 'babylon check' automated triage system. Cornell University. URL: https://arxiv.org/abs/1606.02041 [accessed 2020-07-22]

59. Nadarzynski T, Miles O, Cowie A, Ridge D. Acceptability of artificial intelligence (AI)-led chatbot services in healthcare: a mixed-methods study. Digit Health 2019;5:2055207619871808 [FREE Full text] [doi: 10.1177/2055207619871808] [Medline: 31467682]

60. Razzaki S, Baker A, Perov Y, Middleton K, Baxter J, Mullarkey D, et al. A comparative study of artificial intelligence and human doctors for the purpose of triage and diagnosis. Cornell University. URL: https://arxiv.org/abs/1806.10698 [accessed 2020-07-22]

61. Inkster B, Sarda S, Subramanian V. An empathy-driven, conversational artificial intelligence agent (Wysa) for digital mental well-being: real-world data evaluation mixed-methods study. JMIR Mhealth Uhealth 2018 Nov 23;6(11):e12106 [FREE Full text] [doi: 10.2196/12106] [Medline: $\underline{\text { 30470676] }}$

62. Griol D, Callejas Z. Mobile conversational agents for context-aware care applications. Cogn Comput 2015 Aug 21;8(2):336-356. [doi: 10.1007/s12559-015-9352-x]

63. Griol D, Molina JM, Callejas Z. Towards Emotionally Sensitive Conversational Interfaces for E-therapy. In: Artificial Computation in Biology and Medicine: International Work-Conference on the Interplay Between Natural andArtificial Computation, IWINAC 2015, Elche, Spain, June 1-5, 2015, Proceedings, Part I. Berlin: Springer; 2015.

64. Ly KH, Ly AM, Andersson G. A fully automated conversational agent for promoting mental well-being: a pilot RCT using mixed methods. Internet Interv 2017 Dec;10:39-46 [FREE Full text] [doi: 10.1016/j.invent.2017.10.002] [Medline: 30135751]

65. Comendador BE, Francisco BB, Medenilla JS, Mae S. Pharmabot: A Pediatric Generic Medicine Consultant Chatbot. Journal of Automation and Control Engineering. 2015. URL: http://www.joace.org/index. php? $\mathrm{m}=$ content $\& \mathrm{c}=$ index \&a=show \&catid=42\&id=218 [accessed 2020-07-22]

66. Huang J, Li Q, Xue Y, Cheng T, Xu S, Jia J, et al. TeenChat: A Chatterbot System for Sensing and Releasing Adolescents' Stress. In: International Conference on Health Information Science. Heidelberg: Springer; May 2015:133-145.

67. Kamita T, Ito T, Matsumoto A, Munakata T, Inoue T. A Chatbot System for Mental Healthcare Based on SAT Counseling Method. Mobile Information Systems 2019 Mar 03;2019(2):1-11. [doi: 10.1155/2019/9517321]

68. Kobori Y, Osaka A, Soh S, Okada H. MP15-03 Novel application for sexual transmitted infection screening with an AI chatbot. J Urol 2018 Apr 03;199(4S):1-11. [doi: 10.1016/j.juro.2018.02.516]

69. Mujeeb S, Hafeez M, Arshad T. Aquabot: a diagnostic chatbot for achluophobia and autism. Int J Adv Comput Sci Appl 2017 Dec;8(9):39-46. [doi: 10.14569/IJACSA.2017.080930]

70. Sosale A, Shaikh M, Shah A, Chawla R, Makkar B, Kesavadev J, et al. Real-world effectiveness of a digital therapeutic in improving glycaemic control in south asians living with type 2 diabetes. Diabetes 2018 May;67(Supplement 1):866-P-86640. [doi: $10.2337 / \mathrm{db} 18-866-\mathrm{P}]$

71. Danda P, Srivastava BML, Shrivastava M. Vaidya: A Spoken Dialog System for Health Domain. In: Proceedings of the 13th International Conference on Natural Language Processing. 2015 Presented at: International Conference on Natural Language Processing; 2016; Varanasi, India.

72. Wang H, Zhang Q, Ip M, Fai Lau J. Social media-based conversational agents for health management and interventions. Computer 2018 Aug 03;51(8):26-33. [doi: 10.1109/MC.2018.3191249]

73. Elmasri D, Maeder A. A Conversational Agent for an Online Mental Health Intervention. In: Brain Informatics and Health. Cham: Springer; Sep 23, 2016.

74. Ghosh S, Bhatia S, Bhatia A. Quro: facilitating user symptom check using a personalised chatbot-oriented dialogue system. Stud Health Technol Inform 2018;252:51-56. [Medline: 30040682]

75. Joerin A, Rauws M, Ackerman ML. Psychological artificial intelligence service, Tess: delivering on-demand support to patients and their caregivers: technical report. Cureus 2019 Jan 28;11(1):e3972 [FREE Full text] [doi: 10.7759/cureus.3972] [Medline: 30956924]

76. Wilson N, MacDonald EJ, Mansoor OD, Morgan J. In bed with Siri and Google Assistant: a comparison of sexual health advice. BMJ 2017 Dec 13;359:j5635. [doi: 10.1136/bmj.j5635] [Medline: 29237603]

77. Ni L, Lu C, Liu N, Liu J. MANDY: towards a smart primary care chatbot application. In: Knowledge and Systems Sciences. Heidelberg: Springer; 2017.

78. van Heerden A, Ntinga X, Vilakazi K. The potential of conversational agents to provide a rapid HIV counseling and testing services. In: International Conference on the Frontiers and Advances in Data Science (FADS). 2016 Presented at: 2017 International Conference on the Frontiers and Advances in Data Science (FADS); 2017; Xi'an, China. [doi: 10.1109/FADS.2017.8253198]

79. Cheng A, Raghavaraju V, Kanugo J, Handrianto YP. Development and evaluation of a healthy coping voice interface application using the Google home for elderly patients with type 2 diabetes. 2018 Presented at: 15th IEEE Annual Consumer Communications \& Networking Conference; Jan, 12-15; Las Vegas, NV, USA. [doi: 10.1109/CCNC.2018.8319283]

80. Fitzpatrick KK, Darcy A, Vierhile M. Delivering cognitive behavior therapy to young adults with symptoms of depression and anxiety using a fully automated conversational agent (Woebot): a randomized controlled trial. JMIR Ment Health 2017 Jun 06;4(2):e19 [FREE Full text] [doi: 10.2196/mental.7785] [Medline: 28588005] 
81. Fulmer R, Joerin A, Gentile B, Lakerink L, Rauws M. Using psychological artificial intelligence (Tess) to relieve symptoms of depression and anxiety: randomized controlled trial. JMIR Ment Health 2018 Dec 13;5(4):e64 [FREE Full text] [doi: 10.2196/mental.9782] [Medline: $\underline{30545815}$ ]

82. Galescu L, Allen J, Ferguson G, Quinn J, Swift M. Speech recognition in a dialog system for patient health monitoring. 2009 Presented at: 2009 IEEE International Conference on Bioinformatics and Biomedicine Workshops; November 1-4, 2009; Washington, DC, USA. [doi: 10.1109/BIBMW.2009.5332111]

83. Liu B, Sundar SS. Should machines express sympathy and empathy? Experiments with a health advice chatbot. Cyberpsychol Behav Soc Netw 2018 Oct;21(10):625-636. [doi: 10.1089/cyber.2018.0110] [Medline: 30334655]

84. Miner AS, Milstein A, Schueller S, Hegde R, Mangurian C, Linos E. Smartphone-based conversational agents and responses to questions about mental health, interpersonal violence, and physical health. JAMA Intern Med 2016 May 01;176(5):619-625 [FREE Full text] [doi: 10.1001/jamainternmed.2016.0400] [Medline: 26974260]

85. Rhee H, Allen J, Mammen J, Swift M. Mobile phone-based asthma self-management aid for adolescents (mASMAA): a feasibility study. Patient Prefer Adherence 2014;8:63-72 [FREE Full text] [doi: 10.2147/PPA.S53504] [Medline: 24470755]

86. Stein N, Brooks K. A fully automated conversational artificial intelligence for weight loss: longitudinal observational study among overweight and obese adults. JMIR Diabetes 2017 Nov 01;2(2):e28 [FREE Full text] [doi: 10.2196/diabetes.8590] [Medline: 30291087]

87. Bickmore TW, Trinh H, Olafsson S, O'Leary TK, Asadi R, Rickles NM, et al. Patient and consumer safety risks when using conversational assistants for medical information: an observational study of Siri, Alexa, and google assistant. J Med Internet Res 2018 Sep 04;20(9):e11510 [FREE Full text] [doi: 10.2196/11510] [Medline: 30181110]

88. Ghandeharioun A, McDuff D, Czerwinski M, Rowan K. EMMA: An Emotionally Intelligent Personal Assistant for Improving Wellbeing. Researchgate. URL: https://www.researchgate.net/publication/

330035444_EMMA_An_Emotionally_Intelligent_Personal_Assistant_for_Improving_Wellbeing [accessed 2020-07-22]

89. Kocielnik R, Xiao L, Avrahami D, Hsieh G. Reflection Companion: a conversational system for engaging users in reflection on physical activity. Proc ACM Interact Mob Wearable Ubiquitous Technol 2018 Jul 05;2(2):1-26. [doi: 10.1145/3214273]

90. Kowatsch T, Nißen M, Rüegger D, Stieger M, Flückiger C, Allemand M. The impact of interpersonal closeness cues in text-based healthcare chatbots on attachment bond and the desire to continue interacting: an experimental design. University of Zurich. URL: https://www.zora.uzh.ch/id/eprint/158352/1/

Kowatsch\%2520et\%2520al\%25202018\%2520InterPersCloseness-of-THCB.pdf [accessed 2020-07-22]

91. ReDial: Recommendation dialogs for bridging the gap between chit-chat and goal-oriented chatbots. Microsoft. URL: https://www.microsoft.com/en-us/research/blog/ redial-recommendation-dialogs-for-bridging-the-gap-between-chit-chat-and-goal-oriented-chatbots/ [accessed 2020-07-22]

92. Onwumere J, Amaral F, Valmaggia LR. Digital technology for caregivers of people with psychosis: systematic review. JMIR Ment Health 2018 Sep 05;5(3):e55 [FREE Full text] [doi: 10.2196/mental.9857] [Medline: $\underline{30185402]}$

93. Ruggiano N, Brown EL, Li J, Scaccianoce M. Rural Dementia Caregivers and Technology: What Is the Evidence? Res Gerontol Nurs 2018 Jul 01;11(4):216-224. [doi: 10.3928/19404921-20180628-04] [Medline: $\underline{\text { 30036405] }}$

94. Lee K, Kwon H, Lee B, Lee G, Lee JH, Park YR, et al. Effect of self-monitoring on long-term patient engagement with mobile health applications. PLoS One 2018;13(7):e0201166 [FREE Full text] [doi: 10.1371/journal.pone.0201166] [Medline: 30048546]

95. Coiera E. Paper Review: the Babylon Chatbot. Wordpress. URL: https://coiera.com/2018/06/29/ paper-review-the-babylon-chatbot/ [accessed 2020-07-22]

96. Thompson D, Baranowski T. Chatbots as extenders of pediatric obesity intervention: an invited commentary on 'Feasibility of Pediatric Obesity \& Pre-Diabetes Treatment Support through Tess, the AI Behavioral Coaching Chatbot'. Transl Behav Med 2019 May 16;9(3):448-450. [doi: 10.1093/tbm/ibz065] [Medline: 31094432]

97. D'Alfonso S, Santesteban-Echarri O, Rice S, Wadley G, Lederman R, Miles C, et al. Artificial intelligence-assisted online social therapy for youth mental health. Front Psychol 2017;8:796 [FREE Full text] [doi: 10.3389/fpsyg.2017.00796] [Medline: 28626431]

98. Spinazze P, Bottle A, Car J. Digital health sensing for personalized dermatology. Sensors (Basel) 2019 Aug 5;19(15):3426. [doi: 10.3390/s19153426] [Medline: $\underline{31387237]}$

99. Pal K, Dack C, Ross J, Michie S, May C, Stevenson F, et al. Digital health interventions for adults with type 2 diabetes: qualitative study of patient perspectives on diabetes self-management education and support. J Med Internet Res 2018 Jan 29;20(2):e40 [FREE Full text] [doi: 10.2196/jmir.8439]

100. Bhattarai P, Phillips JL. The role of digital health technologies in management of pain in older people: an integrative review. Arch Gerontol Geriatr 2017;68:14-24. [doi: 10.1016/j.archger.2016.08.008]

101. Devine KA, Viola AS, Coups EJ, Wu YP. Digital health interventions for adolescent and young adult cancer survivors. JCO Clin Cancer Inform 2018;2:1-15. [doi: 10.1200/CCI.17.00138]

102. Amrita DB. Health care social media: expectations of users in a developing country. Med 20 2013;2(2):e4 [FREE Full text] [doi: 10.2196/med20.2720] [Medline: 25075239]

103. Kerr D, Axelrod C, Hoppe C, Klonoff DC. Diabetes and technology in 2030: a utopian or dystopian future? Diabet Med 2018 Apr;35(4):498-503. [doi: 10.1111/dme.13586] [Medline: 29356078] 
104. Mascitti I, Feituri M, Funghi F, Correnti S. COACH BOT: Modular e-course with virtual coach tool support. In: Proceedings of the International Conference on Agents and Artificial Intelligence. 2010 Jul 01 Presented at: International Conference on Agents and Artificial Intelligence; 2010; January, 22-24. [doi: 10.5220/0002589901150120]

105. Abashev A, Grigoryev R, Grigorian K, Boyko V. Programming tools for messenger-based chatbot system organization: implication for outpatient and translational medicines. BioNanoSci 2016 Nov 22;7(2):403-407. [doi: 10.1007/S12668-016-0376-9]

106. Ahmad NS, Sanusi MH, Abd Wahab MH, Mustapha A, Sayadi ZA, Saringat MZ. Conversational bot for pharmacy: a natural language approach. 2018 Presented at: 2018 IEEE Conference on Open Systems (ICOS ); 21-22 Nov, 2018; Langkawi Island, Malaysia, Malaysia. [doi: 10.1109/ICOS.2018.8632700]

107. Alexander JA. Computer assisted optometry--a tutorial with examples. Am J Optom Arch Am Acad Optom 1973 Sep;50(9):730-736. [doi: 10.1097/00006324-197309000-00007] [Medline: 4584475]

108. Chatbots Meet eHealth: Automatizing Healthcare. University of Naples. URL: http://ceur-ws.org/Vol-1982/paper6.pdf [accessed 2020-07-22]

109. Atay C, Ireland D, Liddle J, Wiles J, Vogel A, Angus D, et al. P3-404: can a smartphone-based chatbot engage older community group members? The impact of specialised content. Alzheimers Demen 2016 Jul 01;12:P1005-P1006. [doi: 10.1016/j.jalz.2016.06.2070]

110. Improving adherence in automated e-coaching. In: Persuasive Strategies To Improve Driving Behaviour Of Elderly Drivers By A Feedback Approach. Cham: Springer; 2016.

111. Brixey J, Hoegen R, Lan W, Rusow J, Singla K, Yin X. Shihbot: A facebook chatbot for sexual health information on hiv/aids. In: Proceedings of the 18th Annual SIGdial Meeting on Discourse and Dialogue. 2017 Presented at: 18th Annual SIGdial Meeting on Discourse and Dialogue Cite this publication; 2017; Saarbrücken, Germany. [doi: 10.18653/v1/W17-5544]

112. Callejas Z, Griol D, McTear F, López-Cózar R. A virtual coach for active ageing based on sentient computing and m-health. Ambient Assisted Living and Daily Activities 2014:-. [doi: 10.1007/978-3-319-13105-4 10]

113. Cameron G, Cameron D, Megaw G, Bond R, Mulvenna M, O'Neill S. Towards a chatbot for digital counselling. In: Proceedings of the 31st British Computer Society Human Computer Interaction Conference. 2017 Presented at: 31st British Computer Society Human Computer Interaction Conference; 3-6 July, 2017; University of Sunderland, UK. [doi: 10.14236/ewic/HCI2017.24]

114. Cameron G, Cameron D, Megaw G, Bond R. Best Practices for Designing Chatbots in Mental Healthcare-A Case Study on iHelpr. In: Proceedings of the 32nd International BCS Human Computer Interaction Conference. 2018 Presented at: British HCI Conference 2018; 2018; Belfast. [doi: 10.14236/ewic/HCI2018.129]

115. Chung K, Park RC. Chatbot-based heathcare service with a knowledge base for cloud computing. Cluster Comput 2018 Mar 16;22(S1):1925-1937. [doi: 10.1007/s10586-018-2334-5]

116. Cooper A, Ireland D. Designing a chat-bot for non-verbal children on the autism spectrum. Stud Health Technol Inform 2018;252:63-68. [Medline: 30040684]

117. Denecke K, Lutz Hochreutener S, Poepel A, May R. Talking to Ana: A Mobile Self-Anamnesis Application with Conversational User Interface. Cluster Comput 2019 Jan;22(1):-. [doi: 10.1145/3194658.3194670]

118. Dharwadkar R, Deshpande NA. A Medical ChatBot. Int J Comp Trends Technol 2018;60(1):- [FREE Full text]

119. Divya S, Indumathi V, Ishwarya S, Priyasankari M, Devi SK. A self-diagnosis medical chatbot using artificial intelligence. Journal of Web Development and Web Designing 2018;3(1):-.

120. Do HI, Fu WT. Empathic Virual Assistant for Healthcare Information with Positive Emotional Experience. 2016 Presented at: 2016 IEEE International Conference on Healthcare Informatics; 2016; United States.

121. Dubosson F, Schaer R, Savioz R, Schumacher M. Going beyond the relapse peak on social network smoking cessation programmes: ChatBot opportunities. Swiss Med Informatics 2017 Sep 20:-. [doi: 10.4414/smi.33.00397]

122. Fadhil A, Gabrielli S. Addressing challenges in promoting healthy lifestyles: the al-chatbot approach. In: Proceedings of the 11th EAI International Conference on Pervasive Computing Technologies for Healthcare. 2017 Presented at: International Conference on Pervasive Computing Technologies for Healthcare; May 23-26, 2017; Barcelona, Spain. [doi: 10.1145/3154862.3154914]

123. Fadhil A, Villafiorita A. An adaptive learning with gamification \& conversational UIs: The rise of CiboPoliBot. 2017 Presented at: 25th Conference on User Modeling, Adaptation and Personalization; 9-12th July, 2017; Bratislava, Slovakia. [doi: $10.1145 / 3099023.3099112]$

124. Fadhil A, Diaconu M, Gabrielli S, Villafiorita A. CoachAI: A conversational UI assisted e-coaching platform. Cornell Univeristy. 2017. URL: https://arxiv.org/abs/1904.11961 [accessed 2020-07-22]

125. Beyond Patient Monitoring: Conversational Agents Role in Telemedicine \& Healthcare Support For Home-Living Elderly Individuals. Cornell University. URL: https://arxiv.org/abs/1803.06000 [accessed 2020-07-22]

126. Can a Chatbot Determine My Diet?: Addressing Challenges of Chatbot Application for Meal Recommendation. Cornell Univeristy. URL: https://arxiv.org/abs/1802.09100 [accessed 2020-07-22]

127. A Conversational Interface to Improve Medication Adherence: Towards AI Support in Patient's Treatment. Cornell University. URL: https://arxiv.org/abs/1803.09844 [accessed 2020-07-22] 
128. Fadhil A, Wang Y, Reiterer H. Assistive conversational agent for health coaching: a validation study. Methods Inf Med 2019 Jun;58(1):9-23. [doi: 10.1055/s-0039-1688757] [Medline: 31117129]

129. CARDIAC: An intelligent conversational assistant for chronic heart failure patient heath monitoring. Researchgate. URL: https://www.researchgate.net/publication/ 228374471 CARDIAC An intelligent conversational assistant for chronic heart failure patient heath monitoring [accessed 2020-07-22]

130. Ferguson G, Quinn J, Horwitz C, Swift M, Allen J, Galescu L. Towards a personal health management assistant. J Biomed Inform 2010 Oct;43(5 Suppl):S13-S16 [FREE Full text] [doi: 10.1016/j.jbi.2010.05.014] [Medline: 20937478]

131. Implementation and feasibility study of a tailored health education bot in Telegram for mothers of children with obesity and overweight. Researchgate. URL: https://tinyurl.com/y49e6xsj [accessed 2020-07-22]

132. From Books to Bots: Using Medical Literature to Create a Chat Bot. Researchgate. URL: https://www.researchgate.net/ publication/304358640 From Books to Bots Using Medical Literature to Create a Chat Bot [accessed 2020-07-22]

133. SLOWBot (chatbot) Lifestyle Assistant. ACM Digital Library. URL: https://dl.acm.org/doi/10.1145/3240925.3240953 [accessed 2020-07-22]

134. Conversational System to Assist the User when Accessing Web Sources in the Medical Domain. ResearchGate. URL: https://www.researchgate.net/publication/

261031810 Conversational System to Assist the User when Accessing Web Sources in the Medical Domain [accessed 2020-07-22]

135. Hassoon A, Schrack J, Naiman D, Lansey D, Baig Y, Stearns V, et al. Increasing physical activity amongst overweight and obese cancer survivors using an alexa-based intelligent agent for patient coaching: protocol for the physical activity by technology help (PATH) trial. JMIR Res Protoc 2018 Feb 12;7(2):e27 [FREE Full text] [doi: 10.2196/resprot.9096] [Medline: 29434016]

136. Allergybot: A chatbot technology intervention for young adults with food allergies dining out. Proceedings of the 2017 CHI Conference Extended Abstracts on Human Factors in Computing Systems. 2017. URL: https://www.semanticscholar.org/ paper/A-Conversational-System-to-Assist-the-User-when-Web-Gatius-Namsrai/b6e0f6874204f77fea2b57005470f17e1d5f8d3f [accessed 2020-07-22]

137. Cooper A, Ireland D. Designing a chat-bot for non-verbal children on the autism spectrum. Stud Health Technol Inform 2018;252:63-68. [Medline: 30040684]

138. Chat-Bots for People with Parkinson's Disease: Science Fiction or Reality? Studies in health technology and informatics. URL: https://www.researchgate.net/publication/ 280726980_Chat-Bots_for_People_with_Parkinson's_Disease_Science_Fiction_or_Reality [accessed 2020-07-22]

139. Hello Harlie: Enabling Speech Monitoring Through Chat-Bot Conversations. Studies in health technology and informatics. URL: https://www.researchgate.net/publication/

323104602_Hello_Harlie_Enabling_Speech_Monitoring_Through_Chat-Bot_Conversations [accessed 2020-07-22]

140. Kanagarajan K, Saradha A. An intelligent conversation agent for health care domain. IJSC 2014 Apr 01;4(3):772-776. [doi: 10.21917/ijsc.2014.0110]

141. Kramer JN, Künzler F, Mishra V, Presset B, Kotz D, Smith S, et al. Investigating intervention components and exploring states of receptivity for a smartphone app to promote physical activity: protocol of a microrandomized trial. JMIR Res Protoc 2019 Jan 31;8(1):e11540 [FREE Full text] [doi: 10.2196/11540] [Medline: 30702430]

142. Oh KJ, Lee DK, Ko BS, Hyeon J, Choi HJ. Empathy bot: conversational service for psychiatric counseling with chat assistant. Stud Health Technol Inform 2017;245:1235. [Medline: 29295322]

143. Lee D, Oh KJ, Choi HJ. The chatbot feels you - a counseling service using emotional response generation. 2017 Presented at: IEEE International Conference on Big Data and Smart Computing (BigComp); February 13-16, 2017; Jeju Island, Korea. [doi: 10.1109/BIGCOMP.2017.7881752]

144. Lokman AS, Zain JM. One-match and all-match categories for keywords matching in chatbot. Am J Appl Sci 2010 Oct 01;7(10):1406-1411. [doi: 10.3844/ajassp.2010.1406.1411]

145. An architectural design of Virtual Dietitian (ViDi) for diabetic patients. IEEE Explore. 2009. URL: https://ieeexplore. ieee.org/document/5234671?reload=true\&arnumber=5234671 [accessed 2020-07-22]

146. Designing a Chatbot for diabetic patients. International Conference on Software Engineering \& Computer Systems. URL: https://www.researchgate.net/publication/266872926 Designing a Chatbot for Diabetic Patients [accessed 2020-07-22]

147. A novel approach for medical assistance using trained chatbot. ResearchGate. URL: https://www.researchgate.net/publication/ 318474956_A_novel_approach_for_medical_assistance_using_trained_chatbot [accessed 2020-07-22]

148. Marciel KK, Saiman L, Quittell LM, Dawkins K, Quittner AL. Cell phone intervention to improve adherence: cystic fibrosis care team, patient, and parent perspectives. Pediatr Pulmonol 2010 Feb;45(2):157-164 [FREE Full text] [doi: 10.1002/ppul.21164] [Medline: 20054860]

149. The use of a chatbot in radiology education. European Society of Radiology. URL: https://epos.myesr.org/poster/esr/ ranzcr2018/R-0095 [accessed 2020-07-22] 
150. Morris RR, Kouddous K, Kshirsagar R, Schueller SM. Towards an artificially empathic conversational agent for mental health applications: system design and user perceptions. J Med Internet Res 2018 Jun 26;20(6):e10148 [FREE Full text] [doi: 10.2196/10148] [Medline: 29945856]

151. A Chatbot for Psychiatric Counseling in Mental Healthcare Service Based on Emotional Dialogue Analysis and Sentence Generation. IEEExplore. URL: https://ieeexplore.ieee.org/document/7962482 [accessed 2020-07-22]

152. Likita: A Medical Chatbot To Improve HealthCare Delivery In Africa. Extended Abstracts of the 2018 CHI Conference on Human Factors in Computing Systems. URL: https://www.researchgate.net/publication/ 330522151 Likita A Medical Chatbot To Improve HealthCare Delivery In Africa [accessed 2020-07-22]

153. Chatbot Dimensions that Matter: Lessons from the Trenches. Web Engineering. URL: https://link.springer.com/chapter/ 10.1007/978-3-319-91662-0_9 [accessed 2020-07-22]

154. Automated Medical Chatbot. SSRN. URL: https://papers.ssrn.com/sol3/papers.cfm?abstract id=3090881 [accessed 2020-07-22]

155. Proposal for the development of a mobile virtual assistant for treatment of tuberculosis (2018). Repositório da Produção USP. URL: https://repositorio.usp.br/item/002939130 [accessed 2020-07-22]

156. SleepBot: encouraging sleep hygiene using an intelligent chatbot. ResearchGate. URL: https://www.researchgate.net/ publication/331428159_SleepBot_encouraging_sleep_hygiene_using_an_intelligent_chatbot [accessed 2020-07-22]

157. HomeNL: Homecare Assistance in Natural Language. An Intelligent Conversational Agent for Hypertensive Patients Management. Centre pour la Communication Scientifique Directe. URL: https://hal.archives-ouvertes.fr/inria-00519752/ [accessed 2020-07-22]

158. Chatbot Utilization for Medical Consultant System. IEEEXplore. URL: https://ieeexplore.ieee.org/document/8621678 [accessed 2020-07-22]

159. Sanative Chatbot For Health Seekers. International Journal of Engineering and Computer Science. URL: http://www.ijecs.in/ index.php/ijecs/article/view/720 [accessed 2020-07-22]

160. MamaBot: a System based on ML and NLP for supporting Women and Families during Pregnancy. Semantic Scholar. URL: https://www.semanticscholar.org/paper/

MamaBot\%3A-a-System-based-on-ML-and-NLP-for-Women-and-Vaira-Bochicchio/ c6ac5cdb449e1e08bc0321a675e88d95b1dc88b6 [accessed 2020-07-22]

161. Chatbots and Conversational Interfaces: Three Domains of Use. CEUR Workshop Proceedings. URL: http://ceur-ws.org/ Vol-2101/paper8.pdf [accessed 2020-07-22]

162. Blanson Henkemans OA, van der Boog PJ, Lindenberg J, van der Mast CA, Neerincx MA, Zwetsloot-Schonk BJ. An online lifestyle diary with a persuasive computer assistant providing feedback on self-management. Technol Health Care 2009;17(3):253-267. [doi: 10.3233/THC-2009-0545] [Medline: 19641261]

163. Towards Fully Automated Psychotherapy for Adults - BAS - Behavioral Activation Scheduling Via Web and Mobile Phone. Semantic Scholar. URL: https://www.semanticscholar.org/paper/

Towards-Fully-Automated-Psychotherapy-for-Adults-Griffioen-Both-Cuijpers/43b3c78317a273c7ec46c1696370bf68e42b30fb [accessed 2020-07-22]

164. Allen J, Ferguson G, Blaylock N, Byron D, Chambers N, Dzikovska M, et al. Chester: towards a personal medication advisor. J Biomed Inform 2006 Oct;39(5):500-513 [FREE Full text] [doi: 10.1016/j.jbi.2006.02.004] [Medline: 16545620]

165. Bickmore TW, Schulman D, Sidner C. Automated interventions for multiple health behaviors using conversational agents. Patient Educ Couns 2013 Aug;92(2):142-148 [FREE Full text] [doi: 10.1016/j.pec.2013.05.011] [Medline: 23763983]

166. Evaluating Quality of Chatbots and Intelligent Conversational Agents. arXiv. URL: https://arxiv.org/ftp/arxiv/papers/1704/ 1704.04579.pdf [accessed 2020-07-22]

167. Conversational Agents and Mental Health: Theory-Informed Assessment of Language and Affect. Stanford Univeristy. URL: http://ilpubs.stanford.edu:8090/1141/1/healthDialog.pdf [accessed 2020-07-22]

168. Rizzo AA, Lange B, Buckwalter JG, Forbell E, Kim J, Sagae K, et al. An intelligent virtual human system for providing healthcare information and support. Stud Health Technol Inform 2011;163:503-509. [Medline: 21335847]

169. Different measurements metrics to evaluate a chatbot system. ACM Digital Library. URL: https://dl.acm.org/doi/10.5555/ 1556328.1556341 [accessed 2020-07-22]

170. Dr. Vdoc: A Medical Chatbot that Acts as a Virtual Doctor. Research \& Reviews: Journal of Medical Science and Technology. URL: http://medicaljournals.stmjournals.in/index.php/RRJoMST/article/view/30 [accessed 2020-07-22]

171. Kazi H, Chowdhry B, Memon Z. MedChatBot: an UMLS based chatbot for medical students. IJCA 2012 Oct 20;55(17):1-5. [doi: $10.5120 / 8844-2886]$

172. Coach Me: A Platform For Promoting Healthy Lifestyle. ResearchGate. URL: https://www.researchgate.net/publication/ 307573372 Coach Me A Platform For Promoting Healthy Lifestyle [accessed 2020-07-22]

173. Bickmore TW, Pfeifer LM, Byron D, Forsythe S, Henault LE, Jack BW, et al. Usability of conversational agents by patients with inadequate health literacy: evidence from two clinical trials. J Health Commun 2010;15 Suppl 2:197-210. [doi:

10.1080/10810730.2010.499991] [Medline: 20845204] 
174. Lindenberg K, Moessner M, Harney J, McLaughlin O, Bauer S. E-health for individualized prevention of eating disorders. Clin Pract Epidemiol Ment Health 2011;7:74-83 [FREE Full text] [doi: 10.2174/1745017901107010074] [Medline: 21687562]

175. Dowling M, Rickwood D. Exploring hope and expectations in the youth mental health online counselling environment. Comp Hum Behav 2016 Feb;55:62-68. [doi: 10.1016/j.chb.2015.08.009]

176. Dowling M, Rickwood D. Investigating individual online synchronous chat counselling processes and treatment outcomes for young people. Adv Ment Health 2015 Jan 30;12(3):216-224. [doi: 10.1080/18374905.2014.11081899]

177. Dowling M, Rickwood D. A naturalistic study of the effects of synchronous online chat counselling on young people's psychological distress, life satisfaction and hope. Couns Psychother Res 2015 Jul 14;15(4):274-283. [doi: 10.1002/capr.12037]

178. Azevedo RF, Morrow D, Graumlich J, Willemsen-Dunlap A, Hasegawa-Johnson M, Huang TS, et al. Using conversational agents to explain medication instructions to older adults. AMIA Annu Symp Proc 2018;2018:185-194 [FREE Full text] [Medline: $\underline{30815056}$ ]

179. Brown RL, McDermott RJ, Marty PJ. A conversational information computer system for health and safety operation: the occupational surveillance interactive system (OSIS). Am Ind Hyg Assoc J 1981 Nov;42(11):824-830. [doi: 10.1080/15298668191420756] [Medline: 7315741]

180. Crutzen R, Bosma H, Havas J, Feron F. What can we learn from a failed trial: insight into non-participation in a chat-based intervention trial for adolescents with psychosocial problems. BMC Res Notes 2014 Nov 20;7:824 [FREE Full text] [doi: 10.1186/1756-0500-7-824] [Medline: 25409911]

181. Denecke K, Tschanz M, Dorner TL, May R. Intelligent conversational agents in healthcare: hype or hope? Stud Health Technol Inform 2019;259:77-84. [Medline: 30923277]

182. Designing for Health Chatbots. Cornell University. URL: https://arxiv.org/abs/1902.09022 [accessed 2020-07-22]

183. Mindbot: A Social-Based Medical Virtual Assistanta. IEEEXplore. URL: https://ieeexplore.ieee.org/document/ 7776377?reload=true [accessed 2020-07-22]

184. Stieger M, Nißen M, Rüegger D, Kowatsch T, Flückiger C, Allemand M. PEACH, a smartphone- and conversational agent-based coaching intervention for intentional personality change: study protocol of a randomized, wait-list controlled trial. BMC Psychol 2018 Sep 04;6(1):43 [FREE Full text] [doi: 10.1186/s40359-018-0257-9] [Medline: $\underline{30180880}$ ]

185. Palanica A, Flaschner P, Thommandram A, Li M, Fossat Y. Physicians' perceptions of chatbots in health care: cross-sectional web-based survey. J Med Internet Res 2019 Apr 05;21(4):e12887 [FREE Full text] [doi: 10.2196/12887] [Medline: 30950796]

186. Intelligent chatbot for analysis and diagnosis of the psychiatric disorders. ResearchGate. URL: https://www.researchgate.net/ publication/ 329416982_INTELLIGENT_CHATBOT_FOR_ANALYSIS_AND_DIAGNOSIS_OF_THE_PSYCHIATRIC_DISORDERS [accessed 2020-07-22]

187. Designing Just-in-time Adaptive Interventions and Healthcare Chatbots with the Open Source Platform MobileCoach. University of St. Gallen. URL: https://www.alexandria.unisg.ch/255053/ [accessed 2020-07-22]

188. Chatbots and the new world of HCI. Interactions. URL: https://interactions.acm.org/archive/view/july-august-2017/ chatbots-and-the-new-world-of-hci [accessed 2020-07-22]

189. Garcia DM, Lopez SS, Donis H. Voice activated virtual assistants personality perceptions and desires- comparing personality evaluation frameworks. 2018 Presented at: British Human Computer Interaction Conference; July 2018; Belfast. [doi: $\underline{10.14236 / \text { ewic/HCI2018.40] }}$

\section{Abbreviations}

AI: artificial intelligence

CBT: cognitive behavioral therapy

ECA: embodied conversational agent

EMBASE: Excerpta Medica database

HIC: high-income country

LMIC: low- and middle-income country

MEDLINE: Medical Literature Analysis and Retrieval System Online

NLP: natural language processing

OCLC: Online Computer Library Center

SAT: structure association technique 
Edited by G Eysenbach; submitted 22.11.19; peer-reviewed by A Kocaballi, E Judica; comments to author 09.12.19; revised version received 11.04.20; accepted 13.06.20; published 07.08.20

Please cite as:

Tudor Car L, Dhinagaran DA, Kyaw BM, Kowatsch T, Joty S, Theng YL, Atun R

Conversational Agents in Health Care: Scoping Review and Conceptual Analysis

$J$ Med Internet Res 2020;22(8):e17158

URL: http://www.jmir.org/2020/8/e17158/

doi: $10.2196 / 17158$

PMID: $\underline{32763886}$

CLorainne Tudor Car, Dhakshenya Ardhithy Dhinagaran, Bhone Myint Kyaw, Tobias Kowatsch, Shafiq Joty, Yin-Leng Theng, Rifat Atun. Originally published in the Journal of Medical Internet Research (http://www.jmir.org), 07.08.2020. This is an open-access article distributed under the terms of the Creative Commons Attribution License (https://creativecommons.org/licenses/by/4.0/), which permits unrestricted use, distribution, and reproduction in any medium, provided the original work, first published in the Journal of Medical Internet Research, is properly cited. The complete bibliographic information, a link to the original publication on http://www.jmir.org/, as well as this copyright and license information must be included. 